\title{
Neuronal deletion of GSK3 $\beta$ increases microtubule speed in the growth cone and enhances axon regeneration via CRMP-2 and independently of MAP1B and CLASP2
}

Márcia A Liz ${ }^{1}$, Fernando M Mar ${ }^{1,2}$, Telma E Santos ${ }^{1}$, Helena I Pimentel ${ }^{1}$, Ana M Marques ${ }^{1}$, Marlene M Morgado ${ }^{1}$, Sílvia Vieira', Vera F Sousa ${ }^{1,2}$, Hayley Pemble ${ }^{3}$, Torsten Wittmann ${ }^{3}$, Calum Sutherland ${ }^{4}$, James R Woodgett ${ }^{5}$ and Mónica M Sousa ${ }^{\text {* }}$

\begin{abstract}
Background: In the adult central nervous system, axonal regeneration is abortive. Regulators of microtubule dynamics have emerged as attractive targets to promote axonal growth following injury as microtubule organization is pivotal for growth cone formation. In this study, we used conditioned neurons with high regenerative capacity to further dissect cytoskeletal mechanisms that might be involved in the gain of intrinsic axon growth capacity.

Results: Following a phospho-site broad signaling pathway screen, we found that in conditioned neurons with high regenerative capacity, decreased glycogen synthase kinase $3 \beta$ (GSK3 $\beta$ ) activity and increased microtubule growth speed in the growth cone were present. To investigate the importance of GSK3 $\beta$ regulation during axonal regeneration in vivo, we used three genetic mouse models with high, intermediate or no GSK3 $\beta$ activity in neurons. Following spinal cord injury, reduced GSK3 $\beta$ levels or complete neuronal deletion of GSK3 $\beta$ led to increased growth cone microtubule growth speed and promoted axon regeneration. While several microtubule-interacting proteins are GSK3 $\beta$ substrates, phospho-mimetic collapsin response mediator protein 2 (T/D-CRMP-2) was sufficient to decrease microtubule growth speed and neurite outgrowth of conditioned neurons and of GSK3 $\beta$-depleted neurons, prevailing over the effect of decreased levels of phosphorylated microtubule-associated protein 1B (MAP1B) and through a mechanism unrelated to decreased levels of phosphorylated cytoplasmic linker associated protein 2 (CLASP2). In addition, phospho-resistant T/A-CRMP-2 counteracted the inhibitory myelin effect on neurite growth, further supporting the GSK3 $\beta-C R M P-2$ relevance during axon regeneration.

Conclusions: Our work shows that increased microtubule growth speed in the growth cone is present in conditions of increased axonal growth, and is achieved following inactivation of the GSK33-CRMP-2 pathway, enhancing axon regeneration through the glial scar. In this context, our results support that a precise control of microtubule dynamics, specifically in the growth cone, is required to optimize axon regrowth.
\end{abstract}

Keywords: GSK3 $\beta$, CRMP-2, Growth cone, Microtubule, Axon regeneration

\footnotetext{
* Correspondence: msousa@ibmc.up.pt

${ }^{1}$ Nerve Regeneration Group, IBMC - Instituto de Biologia Molecular e Celular, 4150-180 Porto, Portugal

Full list of author information is available at the end of the article
}

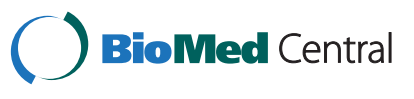

(c) 2014 Liz et al.; licensee BioMed Central Ltd. This is an Open Access article distributed under the terms of the Creative Commons Attribution License (http://creativecommons.org/licenses/by/4.0), which permits unrestricted use, distribution, and reproduction in any medium, provided the original work is properly credited. The Creative Commons Public Domain Dedication waiver (http://creativecommons.org/publicdomain/zero/1.0/) applies to the data made available in this article unless otherwise stated. 


\section{Background}

In the central nervous system (CNS), axons mostly fail to regenerate given the inhibitory environment and the lack of activation of neuronal-intrinsic regenerationassociated pathways. It is, however, possible to stimulate the intrinsic growth capacity of CNS axons. When the peripheral branch of a dorsal root ganglia (DRG) neuron is injured prior to lesion to its central branch (conditioning lesion), the central axons can overcome the glial scar inhibitory effect and regenerate [1]. Although several molecules have been identified as required for the conditioning effect, none was proven to be sufficient and necessary to mimic the conditioning lesion, probably as a combination of various mechanisms is needed.

Microtubule organization is crucial for axon regeneration. While CNS axons respond to injury by forming a retraction bulb with a disorganized network of microtubules, peripheral nervous system (PNS) axons form a growth cone composed by a backbone of stable microtubules and dynamic microtubules in the axon tip [2]. Pharmacological destabilization of microtubules converts a growth cone into a retraction bulb, and stabilization leads to the formation of growth cone-like structures [2] and increases axonal regeneration in vivo, after spinal cord injury (SCI) [3]. Accordingly, histone deacetylase 6 (HDAC6) inhibition enhances tubulin acetylation and promotes axon growth on inhibitory substrates [4]. In contrast, it has been shown that in the PNS, axons have a higher regenerative capacity as they activate a program leading to the activation of histone deacetylase 5 (HDAC5) and to a lower microtubule stability close to the injury site [5].

Here, we further explored the mechanisms underlying the gain of regenerative capacity in conditioned DRG neurons and identified glycogen synthase kinase $3 \beta$ $($ GSK3 $\beta)$ as an important player in this process. GSK3 $\beta$ is a serine/threonine kinase that phosphorylates several microtubule-interacting proteins, namely collapsin response mediator protein 2 (CRMP-2), microtubule-associated proteins (MAP1B and tau), microtubule plus end-tracking proteins (adenomatous polyposis coli and cytoplasmic linker associated protein 2 (CLASP2)) and the microtubuledepolymerizing factor stathmin [6]. The activity of GSK3 $\beta$ is regulated by phosphorylation. Under resting conditions, the kinase is constitutively active following phosphorylation of its Tyr216 residue, located in the kinase domain [7]. The mechanism of Tyr216 phosphorylation has been proposed to correspond to an autocatalytic event [8] although in neurons, kinases such as Pyk2 and Fyn have also been proposed as responsible for this phosphorylation $[9,10]$. Exposure of neuroblastoma cells to the general tyrosine phosphatase inhibitor ortho-vanadate led to increased levels of Tyr216 phosphorylation, raising the hypothesis that a group of yet unidentified tyrosine phosphatases might regulate the phosphorylation of Tyr216 [11]. Nevertheless, regulation of
GSK3 $\beta$ activity is generally seen as resulting from inactivation by phosphorylation of its Ser9 residue [12]. In response to extracellular signals that activate the phosphatidylinositide 3-kinase (PI3K) pathway, protein kinase B (AKT) is activated triggering the inactivation of GSK3 $\beta$ by phosphorylation of Ser9 [13].

The array of GSK3 $\beta$ substrates suggests that it is a key kinase regulating microtubule dynamics and an attractive molecule to study in the context of axon growth. However, controversy exists regarding GSK3 $\beta$ modulation during axonal regeneration as pharmacological inhibition of GSK3 $\beta$ was shown to promote either axonal growth [14] or myelin-dependent axon outgrowth inhibition [15]. While most data relating GSK3 $\beta$ and axonal regeneration relied on semi-specific pharmacological inhibitors tested in vitro, to further determine the relevance of GSK3 $\beta$ during axonal regeneration in vivo, we used three GSK3 $\beta$ genetic mouse models with different levels of kinase activity: constitutively active GSK3ßSer9Ala knockin (KI) mice [16], GSK3 $\beta$ knockout heterozygous mice [17] and mice with neuron-specific deletion of GSK3 $\beta$. Our data show that increased microtubule dynamics in the growth cone are achieved following inactivation of the GSK3 $\beta$-CRMP-2 pathway, enhancing axon regeneration through the glial scar.

\section{Results}

\section{Decreased GSK3 $\beta$ activity through downregulation of} P-Tyr216 is related to increased axonal regeneration

We used the conditioning lesion model $[1,18]$ to identify mechanisms promoting axonal regeneration. For that we analyzed DRGs from rats with either SCI or conditioning lesion using a phospho-site broad signaling pathway screen (Kinexus) that examines 38 phosphorylation sites in 32 key signaling proteins. In the $\mathrm{CL}$ group, $\mathrm{SCI}$ was preceded one week by a sciatic nerve transection. As previously described [1], rats with conditioning lesion had an increased number of dorsal column axons entering the glial scar (Figure 1A), with some axons being capable of regenerating beyond the rostral border of the scar. As expected $[1,18]$, the conditioning effect was also observed in vitro as conditioned DRG neurons (CL; neurons isolated from rats with a sciatic nerve transection performed one week prior to DRG removal) had an increased neurite outgrowth (Figure 1B,C). The analysis of the phospho-site broad signaling pathway screen revealed that following conditioning lesion increased P-AktSer473 (activated Akt), increased P-GSK3ßSer9 (which negatively regulates GSK3 $\beta$ activity), and decreased P-GSK3ßTyr216 were present (Table 1). No differential phosphorylation of GSK3 $\alpha$ was found (Table 1). Combined, these observations indicate that following a conditioning lesion there is an overall decrease of GSK3 $\beta$ activity. Validation was performed by Western blot in DRG (Figure 1D,E,) where we also analyzed samples from 


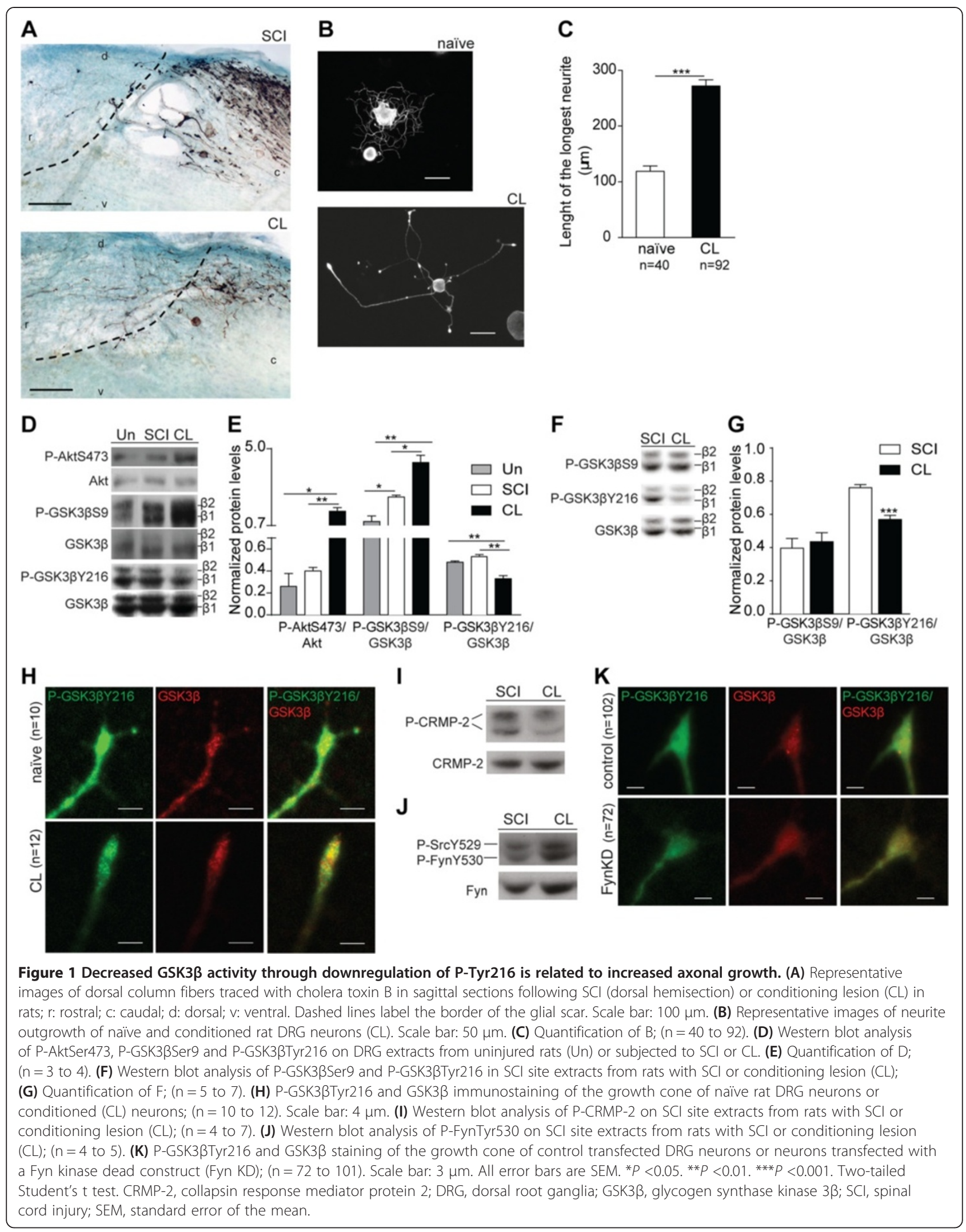


Table 1 Proteins from the GSK3 $\beta$ pathway differentially regulated in DRG after $\mathrm{CL}$ when compared to $\mathrm{SCl}$

\begin{tabular}{ll}
\hline & CL/SCI \\
\hline Protein kinase B alpha (Akt) [S473] & 1,53 \\
Glycogen synthase kinase 3 beta (GSK3 $\beta$ ) [S9] & 1,55 \\
Glycogen synthase kinase 3 beta (GSK3 $\beta$ ) [Y216] & 0,53 \\
Glycogen synthase kinase 3 alpha (GSK3a) [S21] & 0,95 \\
Glycogen synthase kinase 3 alpha (GSK3a) [Y279] & 1,04 \\
\hline
\end{tabular}

$\mathrm{SCl}$, spinal cord injury; $\mathrm{CL}$, conditioning lesion; $\mathrm{DRG}$, dorsal root ganglia.

uninjured animals. After conditioning lesion, increased P-AktSer473 was found relative to both uninjured DRG and DRG collected after SCI (Figure 1D,E). Regarding P-GSK3 3 Ser9, although after SCI the levels were increased relative to uninjured DRG, a more pronounced increase was observed after conditioning lesion (Figure 1D,E). The levels of P-GSK3 3 Tyr216 were decreased after conditioning lesion, when compared to both uninjured DRG and DRG collected after SCI (Figure 1D,E). Locally at the SCI site no differences were found in P-GSK3ßSer9, while P-GSK3ßTyr216 was decreased after conditioning lesion (Figure 1F,G). Accordingly, in the growth cone of conditioned DRG neurons a 1.9-fold decreased ratio $(P<0.0001)$ of P-GSK3 $\beta$ Tyr216/GSK3 $\beta$ was present (Figure $1 \mathrm{H}$ ). The decreased P-GSK3 $\beta$ Tyr216 levels at the SCI site of rats with conditioning lesion correlated with a 1.5 -fold decrease in GSK3 $\beta$ kinase activity $(P<0.05)$ and decreased phosphorylation of CRMP-2 (Figure 1I).

Initial GSK3ßTyr216 phosphorylation occurs through an autocatalytic event [8], although the upstream kinases Pyk2 and Fyn can also target this residue $[9,10]$. Whereas we did not detect Pyk2 either in the DRG or spinal cord, the inactive form of Fyn kinase, P-FynTyr530, was increased after conditioning lesion (Figure 1J; $P<0.01$ ). Moreover, DRG neurons transfected with Fyn kinase dead (Fyn Lys299Met) had a 1.6-fold decreased ratio $(P<0.0001)$ of P-GSK3 $\beta$ Tyr216/GSK3 $\beta$ (Figure 1K) in support of a Fyn kinase-mediated phosphorylation of GSK3 $\beta$ Tyr216 under these conditions. Besides phosphorylation by Fyn kinase, a 1.3-fold higher phosphatase activity against P-GSK3ßTyr216 was found in animals with conditioning lesion $(P<0.05)$ further supporting a tight control of the P-GSK3 $\beta$ Tyr216 levels, probably achieved by dual regulation of upstream kinases and phosphatases.

\section{Enhanced axonal growth in conditioned DRG neurons is related to increased microtubule growth speed in the growth cone}

Our results showed a downregulation of GSK3 $\beta$ activity through decreased GSK3 3 Tyr216 phosphorylation in conditioned neurons. Given the involvement of GSK3 $\beta$ in microtubule dynamics, the microtubule growth rate in naive and conditioned rat DRG neurons was measured. For that, we visualized polymerizing microtubule ends by transfecting neurons with the plus-tip binding protein EB3. When compared to naïve neurons, after conditioning lesion, EB3 comets moved with a 1.8-fold increased speed (Figure 2A,B, see also Additional file 1: Movie S1). Increased microtubule growth speed in conditioned neurons [see Additional file 1: Movie S1] correlated with increased neurite outgrowth (Figure $1 \mathrm{C}$ ). Moreover, by extending the imaging periods, increased axon elongation and increased microtubule growth speed were observed in conditioned neurons, when compared to naïve neurons [see Additional file 2: Movie S2 and Additional file 3: Figure S1]. Regarding the number of growing microtubules, no differences were observed between naïve and conditioned DRG neurons (data not shown). Moreover, in accordance with an increased microtubule growth speed in the growth cone, we observed that the EB3 fluorescence was located within a shorter distance from the growth cone tip in conditioned neurons (Figure 2C,D). This suggests that in conditioned neurons, growth of microtubules into the peripheral domain of the growth cone is promoted. Overall, conditioned DRG neurons exhibited decreased GSK3 $\beta$ activity through downregulation of P-GSK3 $\beta$ Tyr216 and increased microtubule growth speed and growth into the peripheral domain of the growth cone.

\section{In vivo, inhibition of GSK3 $\beta$ via Ser9 phosphorylation is dispensable for gain of axonal regeneration capacity} Given that Ser9 has been widely considered the key regulatory residue of GSK3 $\beta$ [12], we used GSK3ßSer9Ala knockin (KI) mice [16] to further assess its role in vivo during axonal regeneration. In these animals, the endogenous Ser9 codon of GSK3 $\beta$ was changed to encode the nonphosphorylatable Ala residue [16]. GSK3 $\beta$ activity in the spinal cord of GSK3ßSer9Ala KI mice was increased 1.8 -fold when compared to wild type (WT) mice $(P<0.05)$, in agreement with the known inhibitory activity of Ser9 phosphorylation. In vitro, naïve GSK3ßSer9Ala KI DRG neurons displayed a similar neurite outgrowth to that of naive WT neurons and the percentage of longer neurites was increased following conditioning lesion (Figure 3A). In vivo, tracing of dorsal column fibers with cholera toxin subunit B (CT-B) after a spinal cord dorsal hemisection corroborated the in vitro data, with GSK3ßSer9Ala KI axons displaying a similar behavior to that of WT axons (Figure 3B-D). For both genotypes, we observed negligible axonal growth through the glial scar following SCI, whereas an increased number of axons entering the glial scar able to regenerate for longer distances were seen following conditioning lesion (Figure 3B-D). Neither WT nor GSK3ßSer9Ala KI mice showed axons extending rostrally beyond the glial scar, as the conditioning effect is less robust in mice than in rats [19]. These findings demonstrate that modulation of GSK3 $\beta$ through Ser9 phosphorylation 

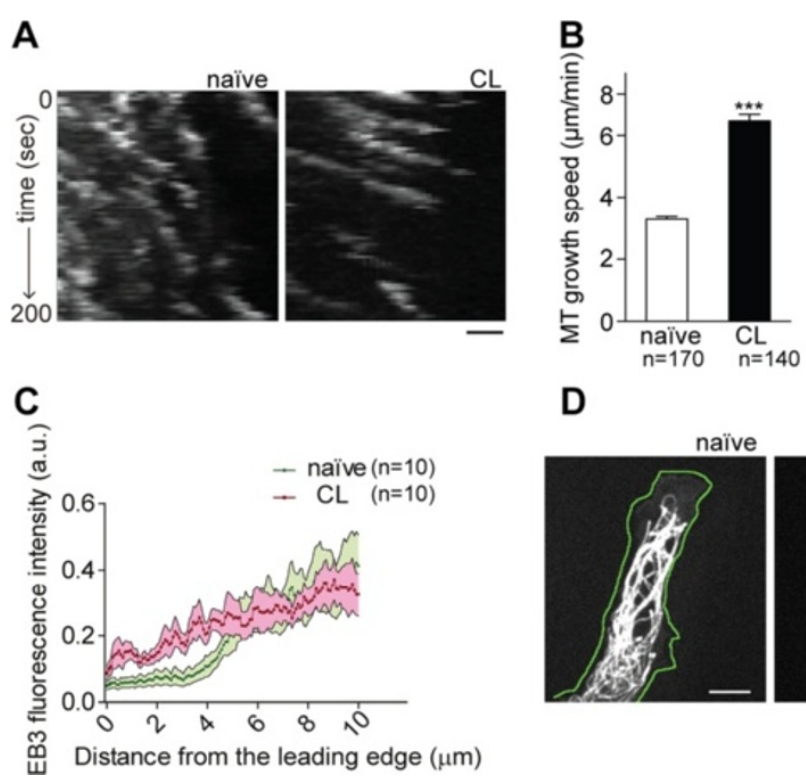

D

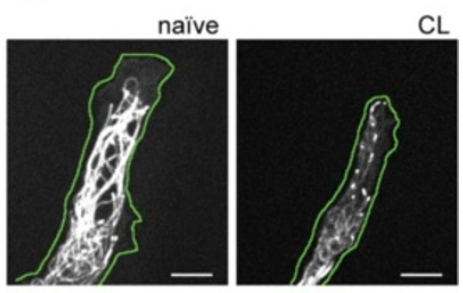

Figure 2 Microtubule growth speed is increased in the growth cone of conditioned DRG neurons. (A) Kymographs of single processes of naïve and conditioned (CL) neurons transfected with EB3-GFP. Scale bar: $1 \mu \mathrm{m}$. (B) Quantification of microtubule growth speed in naïve and in conditioned (CL) neurons transfected with EB3-GFP; ( $n=140$ to 170 microtubules). (C) Quantification of EB3-fluorescence intensity relative to the distance to the growth cone tip in naïve and in conditioned (CL) neurons transfected with EB3-GFP; ( $n=10$ growth cones). For distances closer to the leading edge (between 0.48 and $4.48 \mu \mathrm{m}$ ) the differences presented are statistically significant with $P<0.05$. (D) Representative images of growth cones of naïve and in conditioned $(C L)$ neurons transfected with EB3-GFP. The green line surrounds the leading edge of the cell. Scale bar: $5 \mu \mathrm{m}$. All error bars are SEM. ${ }^{* *} P<0.001$. Two-tailed Student's t test. $C L$, conditioned lesion; DRG, dorsal root ganglia; SEM, standard error of the mean.

is not required to induce axonal growth. Moreover, in the SCI site, both WT and GSK3ßSer9Ala KI mice were able to regulate GSK3 $\beta$ activity through reduced phosphorylation of Tyr216 after conditioning lesion (Figure 3E). In accordance with decreased GSK3 $\beta$ kinase activity after conditioning lesion, the levels of P-CRMP-2 were decreased in the SCI site of both WT and GSK3BSer9Ala KI mice (Figure 3F). These results further support that downregulation of GSK3 $\beta$ activity through decreased Tyr216 phosphorylation represents the primary regulatory event leading to increased axonal growth.

\section{Partial reduction of GSK3 $\beta$ activity increases axonal growth through the glial scar}

To further demonstrate that decreased GSK3 $\beta$ activity is related to increased axonal growth, we assessed axonal regeneration in GSK3 $\beta$ knockout heterozygous mice (GSK3 $\beta$ $(+/-))$ [17]. As expected, GSK3 $\beta(+/-)$ mice exhibit an approximately $50 \%$ reduction of GSK3 $\beta$ kinase activity in the spinal cord $(P<0.05)$. Assessment of axonal regeneration of ascending dorsal column fibers after a dorsal spinal cord hemisection by tracing with CT-B (Figure 4A) showed that GSK3 $3(+/-)$ mice have an increased number of axons inside the glial scar (Figure 4C) and that these are capable of regenerating for longer distances (WT: $39.0 \pm 7.8$, and GSK3 $\beta(+/-): 111.7 \pm 32.4 \mu \mathrm{m} ; P<0.05)$. The conditioning lesion is a very useful model to understand mechanisms underlying central axon regeneration and several molecules initially identified using this paradigm were later found to increase regeneration of other unrelated tracts. To evaluate whether downregulation of GSK3 $\beta$ activity might promote axonal regeneration of other tracts, regeneration of serotonergic axons was assessed. 5-Hydroxytryptamine (5$\mathrm{HT}$ ) immunostaining of descending raphespinal serotonergic axons after complete spinal cord transection (Figure 4B) showed that the number of 5-HT-positive axons caudal to the lesion site was increased 17.4-fold in GSK3 $\beta(+/-)$ mice (Figure $4 \mathrm{C}$ ). This demonstrates that in a non-sensory tract, lower levels of GSK3 $\beta$ increase axonal regeneration through and beyond the glial scar. Of note, the basal levels of 5-HT immunostaining in uninjured spinal cords were similar between WT and GSK3 $\beta(+/-)$ mice (data not shown). The increased regeneration of GSK3 $\beta(+/-)$ serotonergic axons correlated with an improved recovery of open field locomotor activity (Figure 4D), as expected given the modulation by serotonergic axons of the activity of spinal motor systems [20]. Uninjured mice of both genotypes displayed similar maximum locomotor scores. We excluded the possibility that differences in axonal regeneration in GSK3 $\beta(+/-)$ mice might be related to stimulation of astrocyte migration [21] as the glial scar, assessed by the glial fibrillary acidic protein (GFAP)-negative area, remained similar between the 

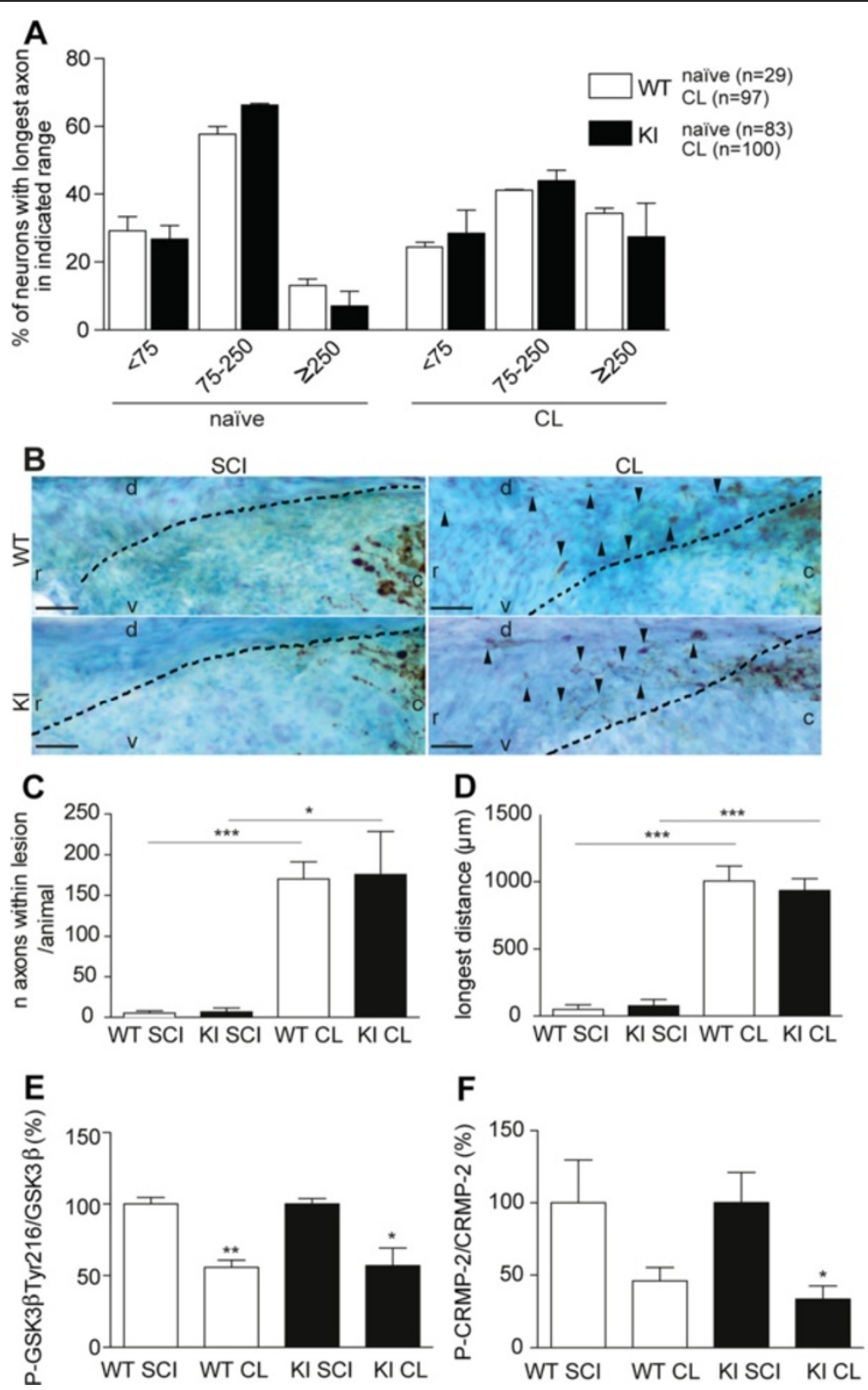

Figure 3 In vivo, inhibition of GSK3 $\beta$ via Ser9 phosphorylation is dispensable for gain of axonal regeneration capacity. (A)

Quantification of neurite outgrowth, measured as the percentage of neurons with the longest axon within each range ( $<75 \mu \mathrm{m}, 75$ to $250 \mu \mathrm{m}$, or $\geq 250 \mu \mathrm{m}$ ), of naïve and conditioned (CL) DRG neurons from either WT or GSK3BSer9Ala KI mice (KI); $(n=29$ to 100). (B) Representative images of CT-B + fibers in sagittal spinal cord sections following SCI (left panels) or conditioning lesion (right panels) in WT (upper panels) and GSK3ßSer9Ala $\mathrm{KI}$ mice (lower panels). r: rostral; c: caudal; d: dorsal; v: ventral; arrowheads highlight axons regenerating rostrally to the $\mathrm{SCl}$ site. Dashed lines label the border of the glial scar. Scale bar: $50 \mu \mathrm{m}$. (C) Quantification of the number of CT-B + dorsal column fibers able to enter the glial scar; $(n=4$ to 6). (D) Quantification of the longest distance of regeneration of CT-B + dorsal column fibers scored from the border of the lesion; ( $n=4$ to 6$)$.

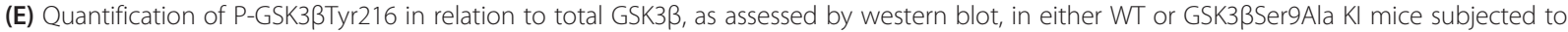
$\mathrm{SCl}(\mathrm{WT} \mathrm{SCl}$ or $\mathrm{KI} \mathrm{SCl}$ ) or conditioning lesion (WT CL or KI CL). Results are presented as a percentage of the $\mathrm{SCl}$ condition. (F) Quantification of P-CRMP-2 in relation to total CRMP-2, as assessed by western blot, in either WT or GSK3ßSer9Ala KI mice subjected to SCI (WT SCI or KI SCI) or conditioning lesion (WT CL or KI CL); $\left(n=3\right.$ to 4). Results are presented as a percentage of the $\mathrm{SCl}$ condition. All error bars are SEM. ${ }^{*} P<0.05$. ${ }^{* *} P<0.01$. ${ }^{* *} P<0.001$. Two-tailed Student's $t$ test. CRMP-2, collapsin response mediator protein 2; DRG, dorsal root ganglia; GSK3 $\beta$, glycogen synthase kinase $3 \beta ; \mathrm{SCl}$, spinal cord injury; SEM, standard error of the mean; WT, wild type. 

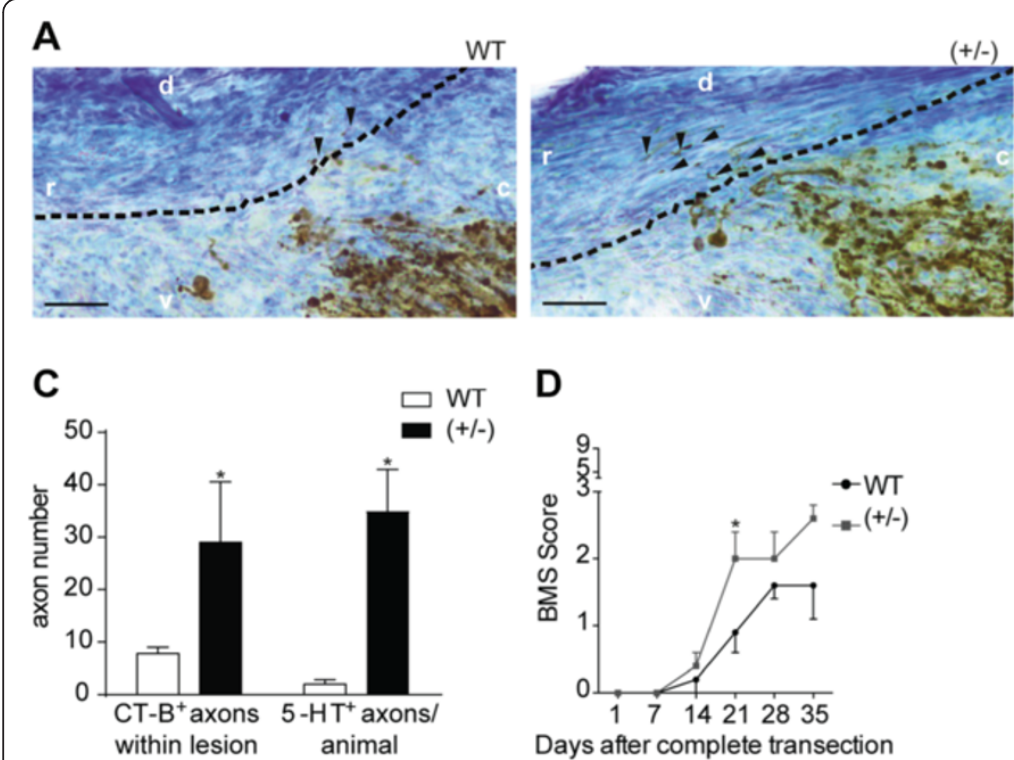

B

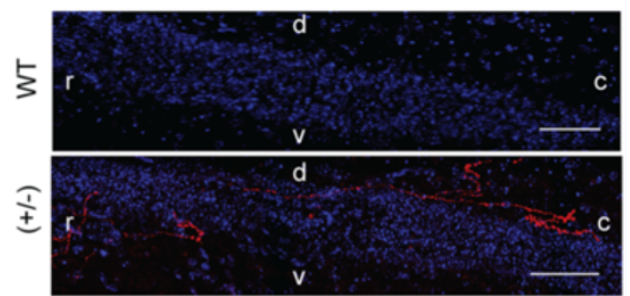

D

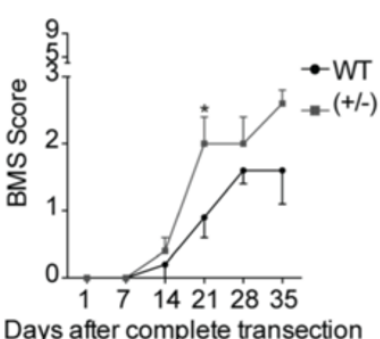

Figure 4 Partial reduction of GSK3 $\beta$ activity increases axonal growth through the glial scar. (A) Representative images of dorsal column fibers traced with CT-B in sagittal sections following dorsal hemisection in WT or GSK3ß(+/-) mice. r: rostral; c: caudal; d: dorsal; v: ventral. Dashed lines label the border of the glial scar. Arrowheads highlight axons regenerating rostrally to the SCI site. Scale bar: 50 um. (B) Representative images of 5-HT-immunostained serotonergic axons (red) counterstained with DAPI (blue) observed caudal to the lesion site in sagittal spinal cord sections following a complete transection in WT or GSK3 $3(+/-)$ mice; ( $n=5$ to 6). Scale bar: $50 \mu m$. (C) Number of CT-B + dorsal column axons able to enter the glial scar following dorsal hemisection (CT-B+) and of 5-HT-immunostained serotonergic axons observed caudal to the lesion site following a complete transection (5-HT+) in WT or GSK3 $(+/-)$ mice. (D) Basso Mouse Scale (BMS) open field test following a complete spinal cord transection in WT and GSK3 $\beta(+/-)$ mice; ( $n=6$ to 7). All error bars are SEM. * $P<0.05$. Two-tailed Student's $t$ test. DAPI, 4',6-diamidino-

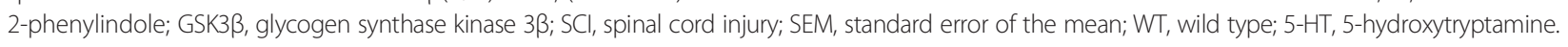

two strains (data not shown). These results show that partial reduction of GSK3 $\beta$ increases axonal growth following SCI.

\section{Neuronal deletion of GSK3 $\beta$ promotes axonal regeneration in the CNS}

To avoid possible confounding effects of GSK3 $\beta$ depleted glia, we used mice with an inducible GSK3 $\beta$ neuronal deletion (cre ${ }^{+}$GSK3ßlox/lox mice) generated by crossing GSK3ßlox/ lox [22] with Slick-H mice (that is, mice that co-express both inducible-CreER ${ }^{\mathrm{T} 2}$ and yellow fluorescent protein (YFP) under the control of the Thy1 promoter) [23]. In these animals cre-positive neurons are YFP-positive. In the cre ${ }^{+}$GSK3/lox/lox mice, GSK3 $\beta$ was deleted in $97 \%$ of the $\mathrm{YFP}^{+}$ DRG neurons (Figure 5A), which represented 40\% of all DRG neurons. We did not observe any compensation by alterations in expression of the GSK3 $\alpha$ isoform in the $\mathrm{YFP}^{+}$cells of cre ${ }^{+}$GSK3/lox/lox mice (data not shown). As expected, growth cones of GSK3 $\beta$ depleted neurons had residual levels of PCRMP-2 and P-MAP1B (Figure 5B), probably accounted for by phosphorylation by alternative kinases.

In vitro, DRG neurons from cre $^{+}$GSK3ßlox/lox mice had increased neurite outgrowth with more neurons extending longer neurites $(\geq 200 \mu \mathrm{m})$ (Figure $5 \mathrm{C}$ ). In vivo, after dorsal spinal cord hemisection, tracing with CT-B of $\mathrm{YFP}^{+}$dorsal column fibers corroborated the in vitro findings, as cre $^{+}$GSK3/lox/lox mice had a 9.8-fold increased number of
$\mathrm{CT}-\mathrm{B}+/ \mathrm{YFP}^{+}$axons entering the glial scar (Figure 5D, E). Moreover, the area of the lesion occupied by $\mathrm{YFP}^{+}$axons was increased 1.8-fold in cre $^{+}$GSK3/lox/lox (Figure 5D,F). Since following dorsal hemisection all the dorsal column fibers were transected, $\mathrm{CT}-\mathrm{B}^{+} / \mathrm{YFP}^{+}$axons entering the glial scar reflect axonal regeneration. In the case of $\mathrm{CT}^{-} \mathrm{B}^{-} / \mathrm{YFP}^{+}$ axons, we cannot discard increased collateral sprouting arising from uninjured axons. We did not assess regeneration of raphespinal serotonergic axons as Slick- $\mathrm{H}$ mice do not express Cre recombinase in this tract. Although unrelated to an in vivo regenerative effect of DRG axons, after complete spinal cord transection, open field locomotor recovery was increased in $\mathrm{cre}^{+}$GSK3/lox/lox mice (Figure 5G), further supporting that neuronal deletion of GSK3 $\beta$ promotes regeneration and/or sprouting of other tracts besides the dorsal column tract. Uninjured mice of both genotypes displayed similar maximum locomotor scores. These data indicate that total deletion of GSK3 $\beta$ in neurons increases axonal regeneration in the CNS within the glial scar.

\section{Decreased GSK3 $\beta$ activity leads to increased microtubule growth speed in the growth cone}

To establish a causal effect between decreased GSK3 $\beta$ activity and altered microtubule dynamics in the growth cone, we measured microtubule growth speed in GSK3 $3(+/-)$ 

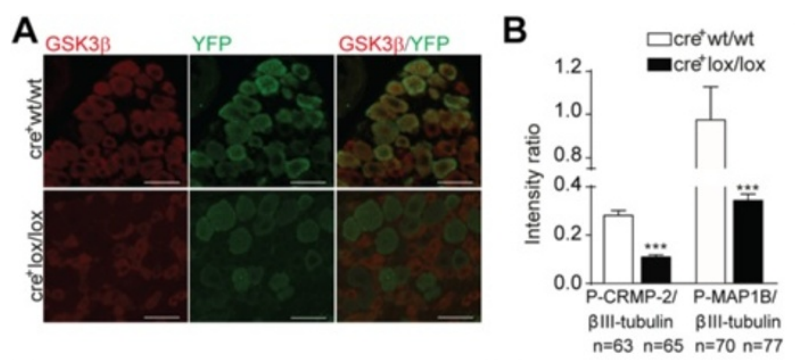

D

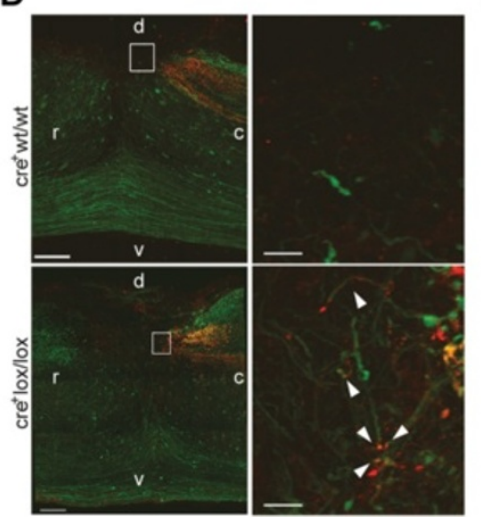

E

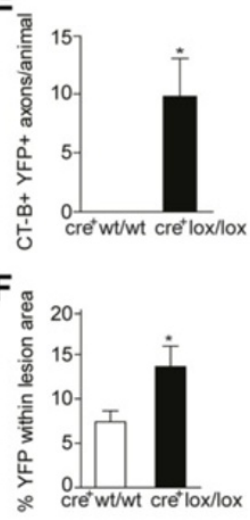

C.

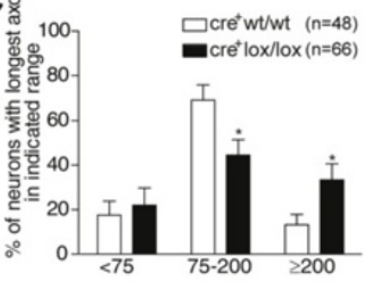

G

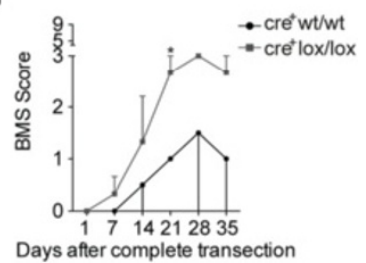

Figure 5 Neuronal GSK3 $\beta$ deletion increases axonal growth. (A) Representative images of GSK3 $\beta$ immunohistochemistry in DRG neurons

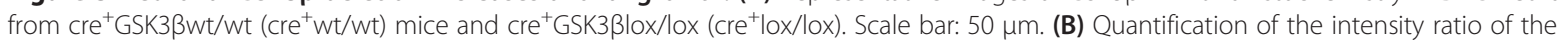

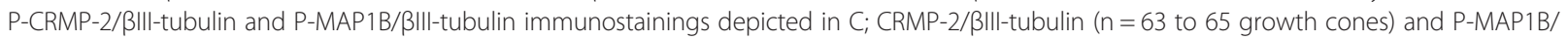

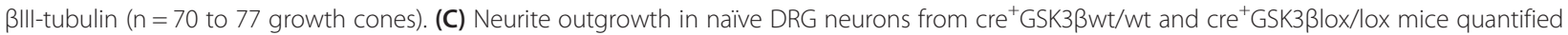
as the percentage of neurons with the longest axon within each range: $<75 \mu \mathrm{m}, 75$ to $200 \mu \mathrm{m}$, or $\geq 200 \mu \mathrm{m}$; $(\mathrm{n}=48$ to 66 ). (D) Representative

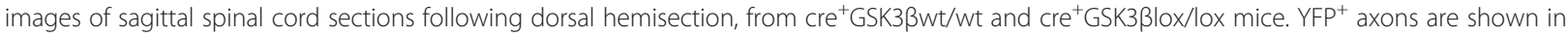
green and dorsal column fibers traced with CT-B are labeled in red; higher magnifications of cre ${ }^{+}$GSK3 $\beta w t / w t$ and $\mathrm{cre}^{+}$GSK3 3 lox/lox showing the $\mathrm{YFP}^{+} / \mathrm{CT}-\mathrm{B}^{+}$axons (arrowheads) within the glial scar are shown on the right. r: rostral; c: caudal; d: dorsal; v: ventral. Scale bar: $25 \mu \mathrm{m}$. (E) Number

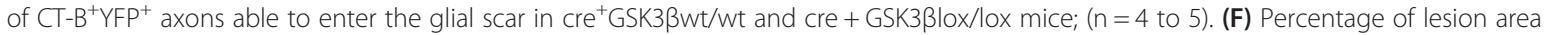
occupied by YFP ${ }^{+}$axons (\% YFP within lesion area) in cre ${ }^{+}$GSK3 $3 w t / w t$ and cre $^{+} G S K 3 \beta l o x / l o x$ mice; $(n=4$ to 5). (G) Locomotor recovery in cre ${ }^{+}$GSK3 $\beta w t / w t$ and cre ${ }^{+}$GSK3ßlox/lox mice assessed by Basso Mouse Scale following complete spinal cord transection. All error bars are SEM. ${ }^{*} P<0.05$. ${ }^{* *} P<0.001$. Two-tailed Student's $t$ test. CRMP, collapsin response mediator protein; GSK3 $\beta$, glycogen synthase kinase 3ß; MAP1B, microtubule-associated protein 1B; SEM, standard error of the mean; YFP, yellow fluorescent protein.

DRG neurons. GSK3 $\beta(+/-)$ neurons had an increased microtubule growth speed in the growth cone (Figure 6A, see also Additional file 4: Movie S3) which correlated with an increased axonal growth as seen by extending the periods of imaging [see Additional file 5: Movie S4 and Additional file 6: Figure S2], similar to what was observed in conditioned DRG neurons (Figure 2B). With respect to the number of EB3 comets, no differences were observed (data not shown). Moreover, GSK3 $\beta(+/-)$ neurons presented EB3 fluorescence located within a shorter distance from the growth cone tip (Figure 6B,C), supporting an increased growth of microtubules into the peripheral domain of the growth cone. Accordingly, a decreased ratio of acetylated (stable)/tyrosinated (dynamic) microtubules in the growth cones of GSK3 $3(+/-)$ neurons was found (Figure $6 \mathrm{D}, \mathrm{E}$ ). In DRG neurons from $\mathrm{cre}^{+}$GSK3ßlox/lox mice, increased microtubule growth speed was present in the growth cone (Figure 6F, see also Additional file 7: Movie S5) and also correlated with increased axonal growth (Figure $5 \mathrm{C}$, see also
Additional file 8: Movie S6 and Additional file 9: Figure S3). Moreover, cre $^{+}$GSK3ßlox/lox neurons also presented a decreased ratio of acetylated/tyrosinated microtubules (Figure 6G,H). Of note, whereas with GSK3 $\beta(+/-$ ) neurons EB3-GFP was used, with $\mathrm{cre}^{+}$GSK3ßlox/lox neurons EB3mCherry was employed as $\mathrm{cre}^{+}$neurons are $\mathrm{YFP}^{+}$. The differences in these constructs (details available in the Methods), might underlie the differences found among controls (WT and cre GSK3ßwt/wt) for the parameters assessed. In summary, these results demonstrate that either partial reduction or total deletion of GSK3 $\beta$ increases microtubule dynamics in the growth cone that correlates with increased axon growth.

Increased microtubule growth speed in the growth cone of GSK3 $\beta$ depleted neurons is related to decreased phosphorylation of CRMP-2

To determine the mechanism underlying the effect of GSK3 $\beta$ in microtubule growth speed, we analyzed the 

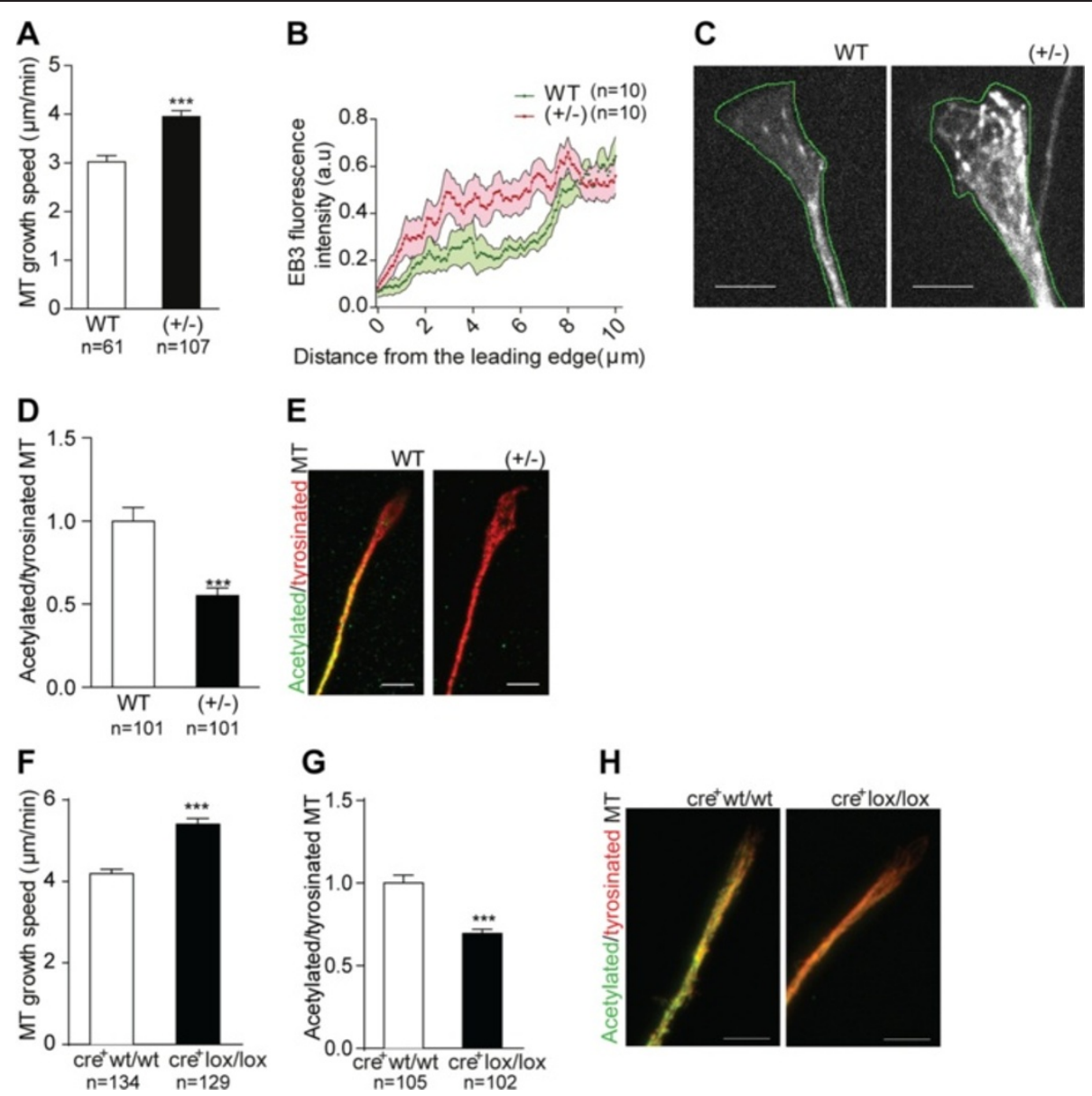

Figure 6 Decreased GSK3 $\beta$ activity leads to increased microtubule dynamics in the growth cone. (A) Quantification of microtubule growth speed in naive DRG neurons from WT or GSK3 $3(+/-)$ mice transfected with EB3-GFP; ( $n=61$ to 107 microtubules). (B) Quantification of EB3fluorescence intensity relative to the distance to the tip of the growth cone, in naïve DRG neurons from WT or GSK3 $\beta(+/-)$ mice transfected with EB3GFP; $(n=10$ growth cones). For distances between 0.80 to $1.12,2.64$ to $3.04,4.64$ to $7.04 \mu \mathrm{m}$ the differences shown are statistically significant with $P$ $<0.05$. (C) Representative images of growth cones of naivve DRG neurons from WT or GSK3 $\beta(+/-)$ mice transfected with EB3-GFP. The green line surrounds the leading edge of the cell. Scale bar: $4 \mu \mathrm{m}$. (D) Quantification of the intensity ratios between acetylated and tyrosinated microtubules in WT or GSK3 $\beta(+/-)$ growth cones; ( $n=101$ growth cones). (E) Representative images of growth cones of naïve DRG neurons from WT or GSK3 $\beta(+/-)$ mice immunostained with acetylated and tyrosinated a-tubulin. Scale bar: $5 \mu \mathrm{m}$. (F) Quantification of microtubule growth speed in naïve neurons

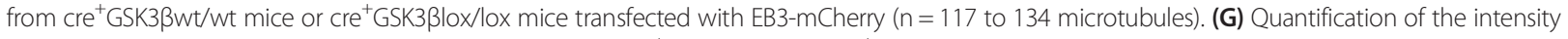

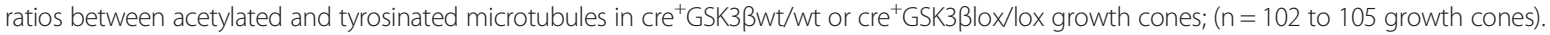
(H) Representative images of growth cones from $\mathrm{cre}^{+} \mathrm{GSK} 3 \beta$ wt/wt or $\mathrm{cre}^{+} \mathrm{GSK} 3 \beta$ lox/lox mice immunostained for acetylated and tyrosinated a-tubulin. Scale bar: $5 \mu \mathrm{m}$. All error bars are SEM. ${ }^{* *} P<0.001$. Two-tailed Student's t test. DRG, dorsal root ganglia; GFP, green fluorescent protein; GSK3 $\beta$, glycogen synthase kinase $3 \beta$; SEM, standard error of the mean. WT, wild type.

role of key GSK3 $\beta$ substrates, namely MAP1B, CLASP2 and CRMP-2. In DRG neuron cultures, the high percentage of satellite cells and the low efficiency of nucleofection and transduction, preclude a straightforward comparison between endogenous and overexpressed protein levels. To allow the comparison of the relative expression of the different mutants analyzed, transfection (for MAP1B and CRMP-2) or transduction (for CLASP2) of a neuronal cell line was performed and revealed similar levels of expression among different mutants (Figure 7A).
Phosphorylation of MAP1B by GSK3 $\beta$ increases microtubule dynamics in non-neuronal cells $[24,25]$. In neurons, overexpression of either WT MAP1B or of the phosphoresistant mutant ST/AA-MAP1B had no significant impact in microtubule growth speed or in the ratio of acetylated/tyrosinated microtubules (Figure 7B-D, see also Additional file 10: Movie S7). However, the phosphomimetic mutant ST/DD-MAP1B increased microtubule growth speed and led to a decreased ratio of acetylated/ tyrosinated microtubules (Figure 7B-D, see also Additional file 10: Movie S7). As such, P-MAP1B in neurons is sufficient 

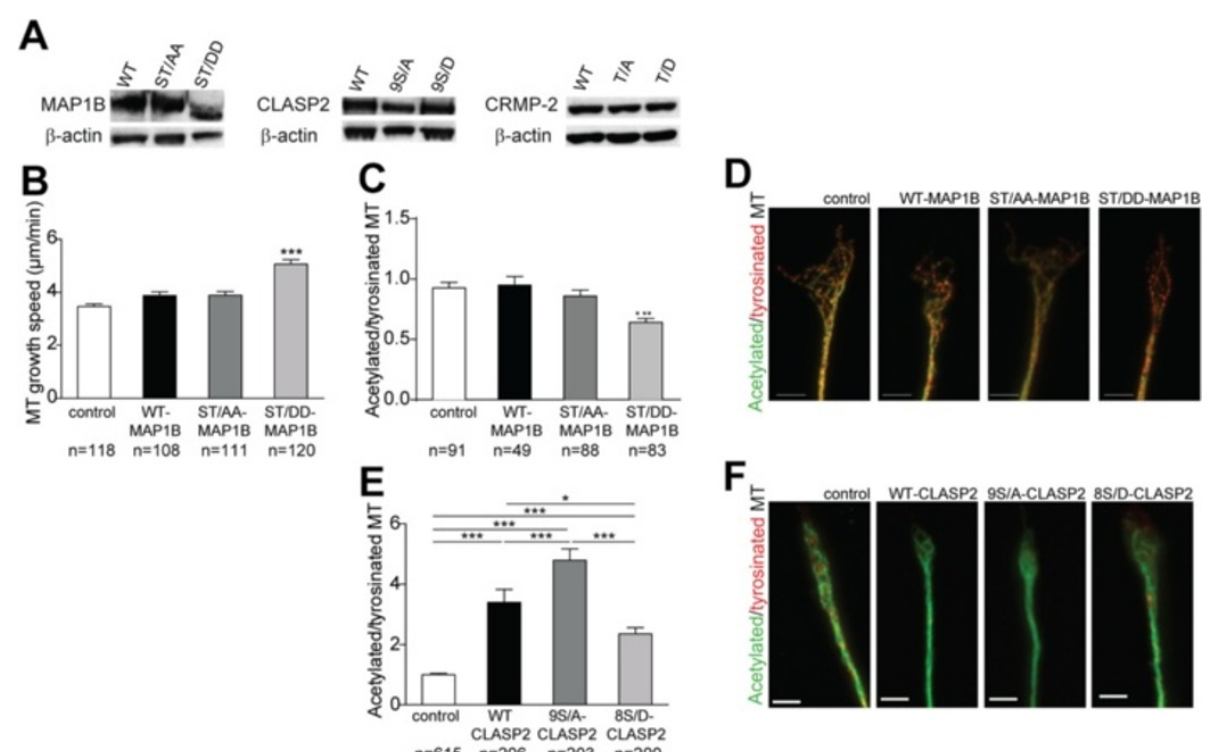

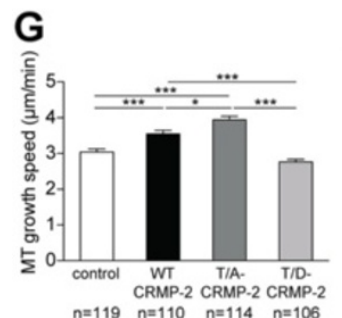

H

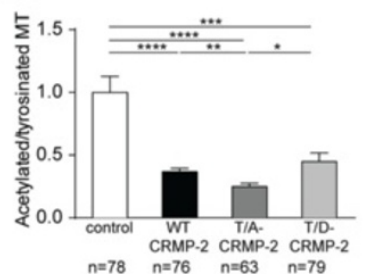

$\mathbf{K}$
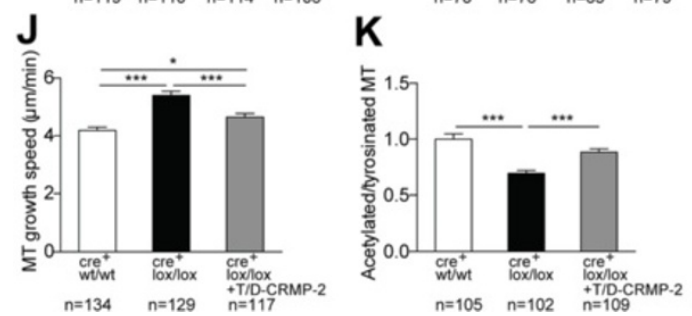

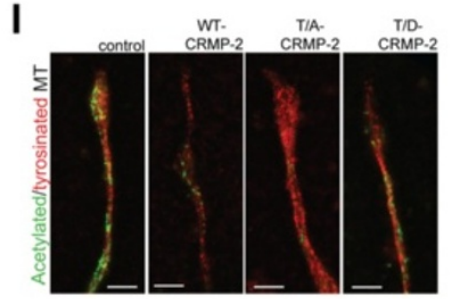

$\mathbf{L}$

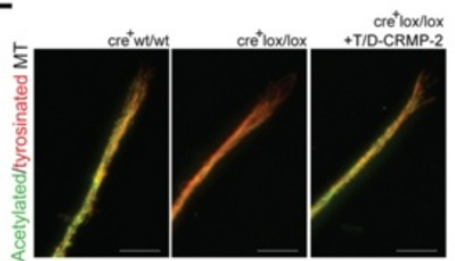

Figure 7 Increased microtubule growth in GSK3 $\beta$ depleted neurons is related to decreased CRMP-2 phosphorylation. (A) MAP1B, CLASP2 and CRMP-2 western in CAD cells. (B) Microtubule growth in rat neurons transfected with EB3-mCherry alone (control) or co-transfected with WT MAP1B, ST/AA-MAP1B or ST/DD-MAP1B. (C) Intensity ratios between acetylated and tyrosinated microtubules in growth cones from rat DRG neurons transfected with EB3-mCherry alone (control) or co-transfected with WT MAP1B, ST/AA-MAP1B or ST/DD-MAP1B. (D) Representative images of C. Scale bar: $3 \mu \mathrm{m}$. (E) Intensity ratios between acetylated and tyrosinated microtubules in growth cones from rat naïve DRG neurons either non-infected (control) or infected with WT CLASP2, 9S/A-CLASP2 or 8S/D-CLASP2. (F) Representative images of E. Scale bar: $3 \mu \mathrm{m}$.

(G) Microtubule growth in neurons transfected with EB3-GFP alone (control) or co-transfected with WT CRMP-2, T/A-CRMP-2, or T/D-CRMP-2.

(H) Intensity ratios between acetylated and tyrosinated microtubules in growth cones from neurons transfected with EB3-GFP alone (control) or co-transfected with WT CRMP-2, T/A-CRMP-2, or T/D-CRMP-2. (I) Representative images of H. Scale bar: 5 um. (J) Microtubule growth in naïve neurons from cre ${ }^{+}$GSK3 $3 w t /$ wt mice or cre+GSK3ßlox/lox mice transfected with EB3-mCherry, or cre $^{+}$GSK3ßlox/lox mice co-transfected with EB3-mCherry and T/D-CRMP-2 (cre GSK3ßlox/lox + T/D-CRMP-2). (K) Intensity ratios between acetylated and tyrosinated microtubules in

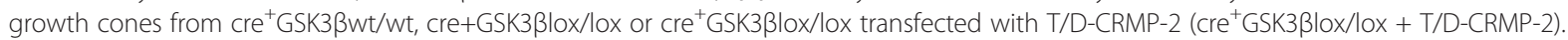
(L) Representative images of K. Scale bar: $5 \mu \mathrm{m}$. All error bars are SEM. ${ }^{* P}<0.05$. ${ }^{* * P}<0.01 .{ }^{* * *} P<0.001 .{ }^{* * * P}<0.0001$. Two-tailed Student's $t$ test. CLASP2, cytoplasmic linker associated protein 2; CRMP, collapsin response mediator protein; DRG, dorsal root ganglia; GSK3 3 , glycogen synthase kinase 33; MAP1B, microtubule-associated protein 1B; SEM, standard error of the mean. WT, wild type.

but not necessary to increase microtubule dynamics, as in GSK3 $\beta$ depleted neurons, reduced levels of P-MAP1B (Figure 5C) and increased microtubule growth speed co-exist.

CLASP2 is a microtubule plus end-binding protein that when overexpressed in COS cells, promotes microtubule stabilization [26]. GSK3 $\beta$ phosphorylates CLASP2 at multiple sites in the domain required for microtubule plus end tracking, disrupting CLASP2 association with microtubules [27]. DRG neurons overexpressing WT CLASP2 had an increased ratio of acetylated/tyrosinated microtubules (Figure 7E,F). Viral transduction with CLASP2 
followed by transfection with EB3 rendered neurons unhealthy for subsequent analyses of microtubule growth speeds. The phospho-resistant mutant 9S/A-CLASP2 promoted an increase in the ratio of acetylated/tyrosinated microtubules more pronounced than WT CLASP2, whereas the phospho-mimetic mutant 8S/D-CLASP2 showed the weakest effect (Figure 7E,F). These results agree with the function of CLASP2 in promoting microtubule stability, which is inhibited by GSK3 $\beta$ phosphorylation. As such, the altered microtubule stability in GSK3 $\beta$ depleted neurons is unrelated to decreased P-CLASP2, suggesting that an alternative GSK3 $\beta$ substrate is responsible for this effect.

CRMP-2 binds to tubulin heterodimers to promote microtubule assembly, thereby enhancing axon elongation, and its microtubule-binding activity is decreased upon GSK3 $\beta$ phosphorylation [28]. In neurons, overexpression of WT CRMP-2 or of the phospho-resistant mutant T/ACRMP-2 led to increased microtubule growth speed (Figure 7G, see also Additional file 11: Movie S8), which was reversed by transfection with the phospho-mimetic mutant T/D-CRMP-2 (Figure 7G, see also Additional file 11: Movie S8). Moreover, overexpression of CRMP-2 decreased the ratio of acetylated/tyrosinated microtubules; this effect being stronger when a phospho-resistant mutant (T/ACRMP-2) was used and less pronounced with the phosphomimetic mutant T/D-CRMP-2 (Figure 7H,I). These results demonstrate that in neurons, the binding of CRMP-2 to tubulin heterodimers in the growth cone controls the rate of microtubule assembly and that this effect is negatively regulated by GSK3 $\beta$ phosphorylation. Moreover, overexpression of T/D-CRMP-2 in cre $^{+}$GSK3ßlox/lox neurons reversed their increased microtubule growth speed (Figure 7J, see also Additional file 7: Movie S5), which correlated with a decreased axon growth [see Additional file 8: Movie S6 and Additional file 9: Figure S3] and a decreased ratio of acetylated/tyrosinated microtubules (Figure 7K,L). Combined, these results demonstrate that neuronal deletion of GSK3 $\beta$ alters the microtubule cytoskeleton in the growth cone, specifically by regulating the levels of P-CRMP-2.

Inactivation of the GSK3 $\beta$-CRMP-2 pathway participates in the conditioning effect attenuating the growth repression mediated by CNS inhibitors

In conditioned DRG neurons, enhanced axonal growth and increased microtubule growth speed in the growth cone are present. At the molecular level, we determined that inhibition of GSK3 $\beta$ activity and decreased levels of P-CRMP-2 occurred in this model. To further demonstrate that the GSK3 $\beta$-CRMP-2 pathway is critical for the conditioning effect, we transfected conditioned DRG neurons with the phospho-mimetic mutant T/D-CRMP-2. Overexpression of phospho-mimetic CRMP-2 partially reversed the increased microtubule growth speed of conditioned neurons (Figure 8A, see also Additional file 1:
Movie S1) and this effect correlated with a decrease in neurite outgrowth (Figure 8B,C, see also Additional file 2: Movie S2 and Additional file 3: Figure S1). A pronounced reversion of the conditioning effect was observed at the level of neurite formation as overexpression of T/DCRMP-2 in conditioned neurons led to a decrease in the percentage of cells with neurites to levels similar to those observed in naïve neurons (Figure 8D). We next assessed whether reducing the levels of P-CRMP-2 by overexpression of T/A-CRMP-2 affected myelin-mediated inhibition of neurite outgrowth in naïve DRG neurons. As expected, purified CNS myelin decreased the growth of the longest DRG neurite (Figure 8E,F). Interestingly, overexpression of phospho-resistant T/A-CRMP-2 counteracted the inhibitory effect of myelin (Figure 8E,F). Together these results demonstrate that inactivation of the GSK3 $\beta$-CRMP2 pathway participates in the conditioning effect overcoming the growth repression mediated by CNS inhibitors.

\section{Discussion}

A conditioning lesion reprograms neurons to a regenerative status. So far, none of the molecules identified as playing a role in this paradigm was shown to be sufficient and necessary to mimic the gain of axonal regenerative capacity elicited, probably as it is obtained through the combination of multiple components. As such, the quest for clinically relevant molecules that contribute to the conditioning lesion effect should be pursued. In this work, we show that the GSK3 $\beta$-CRMP-2 pathway participates in this paradigm, with decreased GSK3 $\beta$ activity and phospho-CRMP-2 levels promoting axonal regeneration and attenuating the growth repression mediated by $\mathrm{CNS}$ inhibitors. The effect of a conditioning lesion in increasing the microtubule growth speed is more robust than that of GSK3 $\beta$ deletion alone, which supports that other pathways might participate in this effect, as is the case in HDAC5 activation [5].

At the mechanistic level, we demonstrate that in vivo, both in WT animals and by blocking Ser9 phosphorylation, GSK3 $\beta$ inhibition occurs through regulation of P-Tyr216 levels. A dual mechanism for the regulation of phosphorylated GSK3 $\beta$ Tyr216 is probably in place after $\mathrm{SCI}$, as increased specific phosphatase activity and decreased Fyn kinase levels are observed in conditions of increased axonal growth. In contrast to our data, after nerve crush injury, both GSK3 $\beta$ P-Ser9 and P-Tyr216 have been reported to be increased both in ipsilateral and contralateral nerves, which causes difficulties in the interpretation of the results [29]. Recently, regulation of axon regeneration through PI3K-GSK3 signaling, occurring through induction of Smad1 expression, was shown to be specific in the soma but dispensable for local axon assembly in the distal axons. Interestingly, this suggested the existence of upstream regulators responsible for 

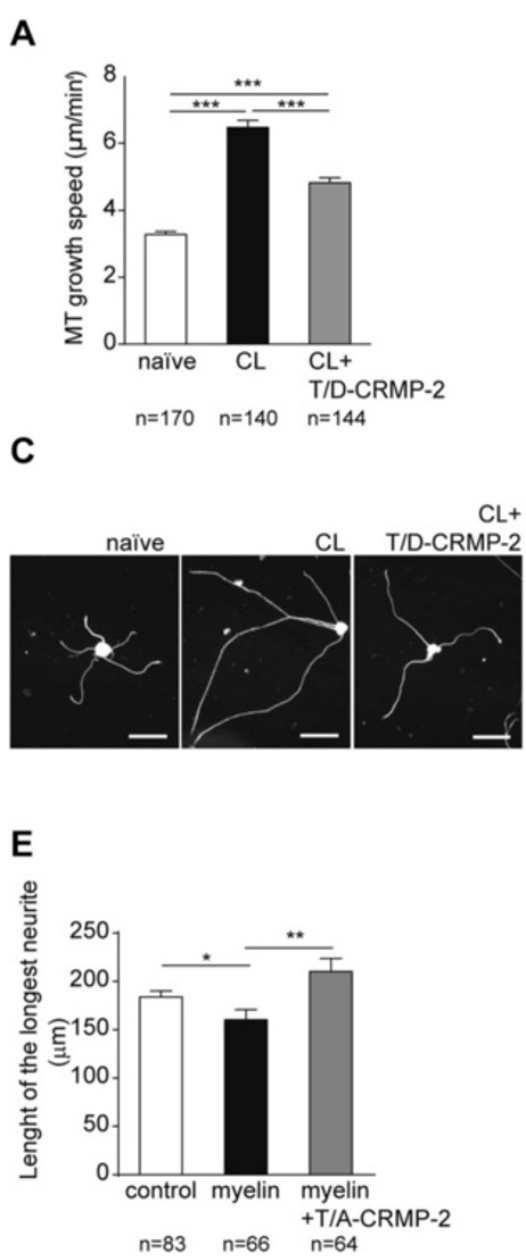

D

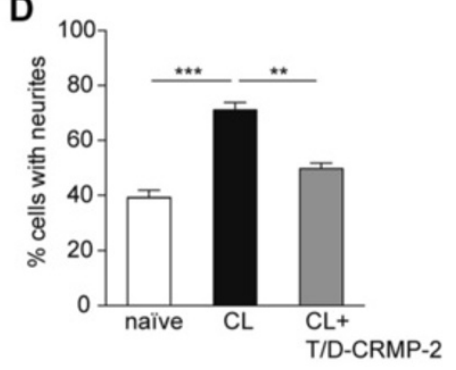

B

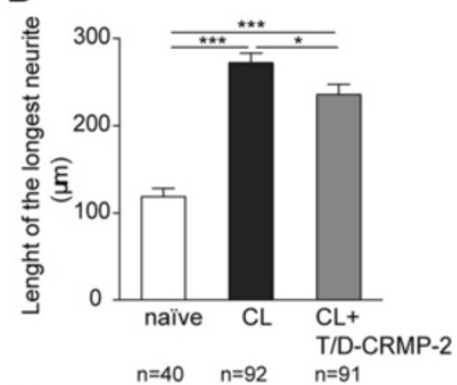

$\mathbf{F}$

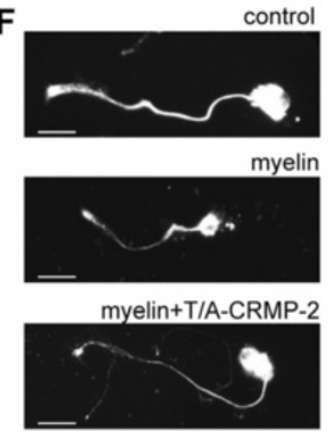

Figure 8 The GSK3 $\beta$-CRMP-2 pathway participates in the conditioning lesion effect. (A) Quantification of microtubule growth speed in naïve and conditioned (CL) DRG neurons transfected with EB3-GFP, or conditioned neurons co-transfected with EB3-GFP and T/D-CRMP-2 ( $C L+$ T/D-CRMP-2); $(n=140$ to 170 microtubules). (B) Quantification of the average size of the longest neurite in naive and conditioned (CL) DRG, or conditioned neurons overexpressing T/D-CRMP-2 (CL + T/D-CRMP-2); $(n=40$ to 91). (C) Representative images of C. Scale bar: $100 \mu m$. (D) Quantification of the percentage of cells with neurites in naïve and conditioned (CL) DRG, or conditioned neurons overexpressing T/D-CRMP-2 ( $C L+T / D-C R M P-2)$. (E) Quantification of the size of the longest neurite of DRG neurons plated on top of laminin (control) or laminin + myelin (myelin), either transfected with pEGFP-C1 or co-transfected with pEGFP-C1 and T/A-CRMP-2 (myelin + T/A-CRMP-2); $(n=64$ to 83). (F) Representative images of F. Scale bar: $30 \mu \mathrm{m}$. All error bars are SEM. ${ }^{*} P<0.05 .{ }^{* *} P<0.01 .{ }^{* *} P<0.001$. One way ANOVA. ANOVA, analysis of variance; CRMP, collapsin response mediator protein; DRG, dorsal root ganglia; GFP, green fluorescent protein; GSK3 $\beta$, glycogen synthase kinase 3 $\beta$; SEM, standard error of the mean.

modulating GSK3 signaling in growth cones of adult sensory neurons [30]. In this respect, we now show that regulation of P-GSK3 $\beta$ Tyr216 levels, achieved by the dual action of upstream kinases and phosphatases, is a possible mechanism responsible for modulating GSK3 activity specifically in growth cones.

Although several studies attempted to understand the role of GSK3 $\beta$ in axon growth and regeneration, as recently reviewed [31], most of the reports used cultured neurons or neuronal cell lines, and semi-specific pharmacological inhibitors, yielding conflicting results ranging from promotion of axon growth to axon growth inhibition. Some in vitro studies suggested that reduced GSK3 $\beta$ activity is required for axon formation, elongation or decreased retraction [28,32-36], in a CRMP-2-dependent mechanism [28,36]. Accordingly, in vivo studies using GSK3 $\beta$ inhibitors showed increased axon regeneration following spinal cord injury [14]. Supporting that in vivo GSK3 $\beta$ inactivation promotes axon regeneration, acutely blocking PI3K signaling or depleting Smad1 in adult mice prevented sensory axon regeneration [30]. Along the same line, other studies suggested that increased GSK3 $\beta$ activity leads to neurite retraction [37]. However, a second group of studies reported opposite effects supporting that increased GSK3 $\beta$ activity leads to increased axon elongation. In this respect, high phosphorylation of GSK3 targets 
(including CMRP-2) was shown to increase neurite elongation [38-40] and pharmacological inhibition or small hairpin RNA (shRNA) blockage of GSK3 $\beta$ activity was reported to induce neurite retraction $[15,41,42]$, with participation of CRMP-4 in the inhibitory effects [15]. The discrepancies in the literature were reconciled with the concept that the final outcome of GSK3 3 inhibition would depend on the extent of inhibition. In this paradigm, partial inactivation of GSK3 $\beta$ in the growth cone would lead to efficient axonal elongation, while strong inhibition would lead to suppression of kinase activity all along the axon, blocking axonal growth [43]. However, as recently suggested [31], a complete understanding of the role of GSK3 $\beta$ in axon growth and regeneration required additional experimentation using in vivo genetic models, as was performed in the current work. Here, we demonstrate that in vivo not only reduced GSK3 3 activity results in increased axon regeneration, but also, by using the cre ${ }^{+}$GSK3/lox/lox mice, we show that total ablation of GSK3 $\beta$ increases axonal regeneration, ruling out the need of a GSK3 $\beta$ gradient to enable axonal growth.

Given the wide array of GSK3 $\beta$ substrates, several studies have probed the downstream molecular mechanism by which GSK3 $\beta$ controls axonal growth. As referred to above, one of the working models was that GSK3 $\beta$ activity should be precisely controlled so that activity towards one subset of substrates would be specifically blocked, while activity towards others would be preserved [43]. In this model, inhibition of GSK3 $\beta$ activity towards CRMP-2 would allow its binding to microtubules promoting their polymerization, while maintenance of the activity towards MAP1B would maintain microtubules in a dynamic state, essential for axon growth. More recently, another model proposed CLASPs as the physiological target of GSK3 to exert control over axon growth [44]. In this model, promotion of axon growth occurred via moderate inhibition of GSK3 activity leading to the non-phosphorylation of some, but not all, GSK3 sites in CLASPs. This would allow CLASPs to specifically associate with microtubule plus ends promoting their stabilization [44]. Both models required partial inhibition of GSK3 $\beta$ to promote axonal growth and regeneration. However, we demonstrate that total GSK3 $\beta$ inhibition promotes axonal growth in vivo with a concomitant increase in microtubule growth speed in the growth cone. In this context, we show that the effects of GSK3 $\beta$ deletion are not mediated by decreased P-CLASP2 as in WT neurons, a non-phosphorylatable CLASP2 mutant leads to increased microtubule stabilization. Moreover, our results show that phosphorylation of MAP1B, although being sufficient to increase microtubule growth speed, is unnecessary for this effect. Interestingly, after SCI, increased levels of phosphorylated MAP1B have been reported in retraction bulbs of transected axons and in pre-apoptotic axotomized neuronal somata [45]. In our settings, overexpression of WT MAP1B did not influence microtubule growth speed. MAP1B was recently shown to interact with $\mathrm{EB} 1 / 3$ and to sequester these proteins [46]. Nevertheless, in that report, microtubule growth speed of MAP1B knockout hippocampal neurons was unaffected in the growth cone [46]. In DRG neurons from MAP1B knockout mice, whereas no differences were found in the overall neurite length, higher branching and impaired growth cone turning were present [47]. These data suggest that rather than playing a role in neurite growth, MAP1B is important for growth cone turning and branch formation during plastic changes in the adult.

More importantly, our results show that CRMP-2 is the primary downstream target of GSK3 $\beta$ that mediates the regulation of microtubule dynamics in the growth cone as demonstrated by reversion of increased microtubule growth speed of GSK3 $\beta$-depleted neurons upon overexpression of a phospho-mimetic CRMP-2 mutant. Moreover, we demonstrate that the GSK3 $\beta-C R M P-2$ pathway participates in the conditioning lesion effect, as overexpression of the phospho-mimetic T/D-CRMP-2 mutant partially reversed the increased microtubule growth speed of conditioned neurons leading to decreased axonal growth, and overexpression of the phospho-resistant T/ACRMP-2 mutant attenuated the inhibitory effect of myelin in naïve DRG neurons. Besides being phosphorylated by GSK3 $\beta$ at Thr514 [39], CRMP-2 is also phosphorylated by Rho-associated protein kinase (ROCK) but at an alternative residue, Thr555 [48], downstream of both Myelin-associated glycoprotein (MAG) and Nogo-66 [49]. Interestingly, repulsive guidance molecule A (RGMa) inhibits axon growth by inducing CRMP-2 phosphorylation via both ROCK and GSK3 3 signaling [36]. However, in that study, details on which CRMP-2 phosphorylation (Thr514 or Thr555) was assessed are lacking, and GSK3 $\beta$ inhibition was performed in cultured neurons using a GSK3 $\beta$ antibody in the media and not a specific cell-permeable GSK3 $\beta$ inhibitor. Taken together, our data demonstrate that, irrespective of ROCK-mediated CRMP-2 phosphorylation at Thr555, inactivation of CRMP-2 phosphorylation at Thr514 by GSK3 3 is sufficient to reverse myelin inhibition in DRG neuron cultures. Our results point towards modulation of CRMP-2 activity as a therapeutic target to induce axonal regeneration. Further suggesting that CRMP-2 is a central target to design strategies to achieve release of myelin inhibition, overexpression of the phospho-resistant mutant T555A-CRMP-2 (the Rhokinase phosphorylation site) counteracts the inhibitory effect of MAG on postnatal cerebellar neurons [49]. Additionally, protein phosphatase $2 \mathrm{~A}$ promotes axonal growth by dephosphorylating CRMP-2 [50]. The involvement of CRMP-2 in several neurodegenerative diseases raised the need for developing therapeutic strategies targeting its 
functions. In this respect, drugs regulating CRMP-2 levels and activity are currently being tested in the settings of neurodegeneration [51].

\section{Conclusions}

Our work shows that microtubule dynamics in the growth cone are higher in conditions of increased axonal growth, such as after conditioning lesion. This alteration is achieved following inactivation of the GSK3 $\beta$-CRMP-2 pathway and is accompanied by enhanced axon regeneration through the glial scar. Based on the present results, studying the effect of CRMP-2-specific drugs, capable of modulating its activity, should be further developed in SCI and in other conditions where axonal regeneration needs to be promoted.

\section{Methods}

\section{Animals}

All animal experiments were performed according to national and European rules. The protocols described in this work have been approved by the IBMC Ethical Committee and by the Portuguese Veterinarian Board. GSK3 $\beta$ knockout heterozygous mice $(\operatorname{GSK} 3 \beta(+/-))$ [17] were bred with C57/B6 mice and the resulting GSK3 $\beta(+/-)$ and WT littermates were selected as described [17]. Homozygous GSK3 $\beta$ Ser9Ala knockin (KI) mice, where codon encoding Ser9 of GSK3 $\beta$ was changed to encode the nonphosphorylatable Ala residue, were a kind gift from Dr Dario Alessi, Dundee University [16]. To generate experimental GSK3 $\beta$ Ser9Ala KI and the respective WT control mice, GSK3 $\beta$ Ser9Ala KIs were initially crossed with C57/B6 mice and the resulting GSK3 $\beta$ Ser9Ala heterozygous KI mice were inter-crossed such that GSK3 $\beta$ Ser9Ala KI and WT animals were generated and selected as described [16]. GSK3 $\beta$ floxed mice (GSK3ßlox/lox) [22] and Slick-H mice (a kind gift from Dr Guoping Feng, Duke University Medical Center; mice that coexpress inducible-CreER ${ }^{\mathrm{T} 2}$ and YFP under the control of the Thy1 promoter [23]) were used to generate neuronal-specific conditional GSK3 $\beta$ knockout mice (cre ${ }^{+}$GSK3 3 lox/lox). For that, GSK3ßlox/ lox were crossed with Slick-H mice. Cre ${ }^{+}$GSK3ßlox/wt mice were selected and then crossed to GSK3ßlox/wt mice such that $\mathrm{cre}^{+}$GSK3 3 lox/lox and $\mathrm{cre}^{+}$GSK3 $\beta$ wt/wt mice were generated. Given the neuroprotective effects of tamoxifen [52,53], tamoxifen-treated $\mathrm{cre}^{+}$GSK3ßlox/lox animals were compared to tamoxifen-treated $\mathrm{cre}^{+} \mathrm{GSK} 3 \beta \mathrm{wt} /$ wt mice. In all experiments animals of either sex were used.

\section{Surgeries}

For sciatic nerve injury, the sciatic nerve was transected at the mid thigh level. For spinal cord injury (SCI), laminectomy was performed at the T7 level in rats and at the T9/ 10 level in mice; dorsal hemisection or complete spinal cord transection were done using a micro feather ophthalmic scalpel. For conditioning lesion, animals were subjected to sciatic nerve transection and one week later to dorsal spinal cord hemisection.

\section{Phospho-site broad signaling pathway screen}

DRGs (L4-L6) from a pool of six rats eight- to tenweeks-old subjected to either SCI (dorsal hemisection) or conditioning lesion (CL) were sacrificed one week after SCI. DRG were homogenized in lysis buffer $(20 \mathrm{mM}$ 4-morpholinepropanesulfonic acid (MOPS), $2 \mathrm{mM}$ ethylene glycol tetraacetic acid (EGTA), $5 \mathrm{mM}$ ethylenediaminetetraacetic acid (EDTA), $30 \mathrm{mM} \mathrm{NaF}, 60 \mathrm{mM}$ $\beta$-glycerophosphate, $20 \mathrm{mM}$ sodium pyrophosphate, $1 \mathrm{mM}$ sodium orthovanadate, $1 \%$ Triton X-100, $1 \%$ dithiothreitol (DTT), $1 \mathrm{mM}$ phenylmethylsulfonyl fluoride (PMSF) and protease inhibitor cocktail (GE Healthcare, Carnaxide, Portugal)). Protein extracts $(500 \mu \mathrm{g})$ were analyzed using the Kinexus phospho-site broad signaling pathway screen version 1.3 (KPSS-1.3, Kinexus Bioinformatics Corp, Vancouver, Canada). This screen examines 38 phosphorylation sites in 32 proteins with antibodies that recognize specific phosphorylated epitopes. The intensities of signals for target protein bands on the Kinetworks immunoblots were quantified as described [54]. Proteins with a fold change CL/SCI lower than 0.75 or higher than 1.25 were selected.

\section{Western blotting}

DRGs (L4-L6) and the SCI site (3 $\mathrm{mm}$ rostral and $3 \mathrm{~mm}$ caudal to the lesion site) from either eight- to ten-weekold rats or WT and GSK3ßSer9Ala KI mice with SCI or conditioning lesion were processed as described above. Lysates of neuronal cultures overexpressing GSK3 $\beta$ substrates (as described below) were prepared in phosphatebuffered saline (PBS) with $0.03 \%$ triton, $1 \mathrm{mM}$ sodium orthovanadate and protease inhibitor cocktail. Protein lysates ( 25 to $50 \mu \mathrm{g} /$ lane) were separated on either $12 \%$ or $3 \%$ to $8 \%$ gradient (in the case of MAP1B and CLASP2) SDS-PAGE gels and transferred to nitrocellulose (Amersham, Carnaxide, Portugal). Membranes were blocked and incubated overnight at $4{ }^{\circ} \mathrm{C}$ in $5 \%$ bovine serum albumin (BSA) in tris-buffered saline with Tween (TBST) with the following primary antibodies: rabbit anti-P-AktSer473 (1:2000; Cell Signaling, Leiden, The Netherlands), rabbit anti-Akt (1:1000; Cell Signaling), rabbit anti-P-GSK3ßSer9 (1:1000; Cell Signaling), rabbit anti-P-GSK3 $\beta$ Tyr216 (1:2000; Santa Cruz Biotechnology, Heidelberg, Germany), mouse anti-GSK3 $\alpha / \beta$ (1:3000; Santa Cruz Biotechnology), sheep anti-P-CRMP-2Thr509/ 514 (1:1000, Kinasource), sheep anti-CRMP-2 (1:500, Kinasource), rabbit anti-P-SrcTyr529 (1:500, Signalway antibody), rabbit anti-Fyn (1:1000, Cell Signaling), goat anti-Pyk2 (1:1000, Santa Cruz Biotechnology), rabbit antiMAP1B (1:2500, kindly provided by Dr Itzhak Fischer, 
Drexel University College of Medicine, Philadelphia, PA, USA), rat anti-CLASP2 (kindly provided by Dr Helder Maiato, IBMC, Porto, Portugal), mouse anti- $\alpha$-tubulin (1:5000, Sigma-Aldrich, Sintra, Portugal), mouse anti- $\beta$-actin (1:1000, Sigma-Aldrich) and mouse anti-glyceraldehyde 3phosphate dehydrogenase (1:2000, Santa Cruz Biotechnology). Incubation with horseradish peroxidase-labeled secondary antibodies was performed for one hour at room temperature. Blots were developed using the enhanced chemiluminescence Western blot substrate (Pierce). Quantification was performed using the QuantityOne software (Bio-rad, Amadora, Portugal). For each experiment representative Western blots are shown.

\section{GSK3 $\beta$ activity assays}

A commercial kit (Sigma) was used for GSK3 $\beta$ activity assays. The samples analyzed were: the SCI site of eight- to ten-week-old rats with SCI or conditioning lesion, and the spinal cord (T8-T10) from eight-week-old GSK3ßSer9Ala KI mice, GSK3 $\beta(+/-)$ mice or the respective WT controls. Briefly, $250 \mu \mathrm{g}$ of protein lysate ( $\mathrm{n}=3$ samples/condition) were incubated with the provided anti-GSK3 $\beta$ antibody in Protein $G$ beads for three hours at $4^{\circ} \mathrm{C}$. The kinase assay was performed in the immunoprecipitates using a GSK3 $\beta$ substrate and $\gamma^{-}{ }^{32} \mathrm{P}$-ATP. Control reactions without GSK3 $\beta$ antibody were performed. Results are presented as fold change relative to controls.

\section{Measurement of phosphatase activity}

Phosphatase activity of the SCI site from eight- to ten-weekold rats with either SCI or conditioning lesion ( $n=3$ per condition) was assayed in 96-well microtiter plates using a tyrosine phosphatase assay system (Promega, Carnaxide, Portugal). Protein extracts $(25 \mu \mathrm{g})$ were incubated with $100 \mu \mathrm{M}$ of a P-GSK3 3 Tyr216 peptide (Abcam, Cambridge, $\mathrm{UK})$ at $30^{\circ} \mathrm{C}$ for 30 minutes. The released phosphate was determined by measuring the absorbance at $620 \mathrm{~nm}$. Control reactions without the P-GSK3 3 Tyr216 peptide were performed.

\section{Primary cultures of DRG neurons and neurite outgrowth assays}

Primary cultures of DRG neurons were performed as described [55]. Briefly, all DRG (when analyzing naïve neurons) or L4-L6 DRG (when comparing naïve with conditioned neurons that is, neurons obtained from animals with sciatic nerve transection performed one week before DRG removal) from eight- to ten-week-old Wistar rats, or whenever indicated, from GSK3 $\beta$ genetic mouse models, were cultured for 12 hours. For transfection, the 4D Nucleofector Amaxa system (Lonza, Barcelona, Spain, CM\#138 program) was used with $0.4 \mu \mathrm{g}$ pmaxGFP ${ }^{\mathrm{mm}}$ (Lonza) or $0.4 \mu \mathrm{g}$ pmaxGFP ${ }^{\mathrm{m}}$ plus $2 \mu \mathrm{g}$ pCMV5-Fyn Lys299Met (Fyn kinase-dead, a kind gift from Dr Marilyn
Resh, Memorial Sloan-Kettering Cancer Center, New York, NY, USA). After transfection, cells were left in suspension for 24 hours and thereafter plated in poly L lysine (PLL)-laminin coated coverslips for 12 hours. For cultures with myelin, DRG neurons were isolated from mice at postnatal day 6 (P6). After transfection, DRG neurons were left in suspension for 24 hours and thereafter plated in PLL-laminin plus $3 \mu \mathrm{g}$ myelin coated coverslips for 12 hours. Myelin was isolated from the spinal cord of 16-week-old WT mice as previously detailed [56]. To measure neurite outgrowth, immunocytochemistry for $\beta I I I-t u b u l i n$ was done. The length of the longest neurite was traced with neuronJ [57]. The number of neurons traced was: for rat DRG neurons, 77 to 136; for GSK3Ser9AlaKI neurons, 29 to 100; for $\mathrm{cre}^{+}$GSK3ßlox/lox neurons, 48 to 66 YFP + neurons.

\section{Overexpression of GSK3 $\beta$ substrates in neuronal cultures}

Substrate residues phosphorylated by GSK3 $\beta$ were mutated to generate phospho-resistant or phospho-mimetic mutants. Mutations were generated by polymerase chain reaction (PCR)-based site-directed mutagenesis using QuickChange XL (Agilent Technologies, Santa Clara, CA, USA). For MAP1B, double mutants of the residues S1260 and T1265 were done to either Ala (ST/AAMAP1B) or Asp (ST/DD-MAP1B) in pEGFP-C1 bearing full-length WT MAP1B. Neurons were co-transfected with EB3-mCherry and each of the MAP1B constructs, and microtubule growth speed was assessed. For CLASP2 adenoviruses, full-length WT or phosphomutant (9S/ACLASP2 or 8S/D-CLASP2) EGFP-CLASP2 $\alpha$ [26] was subcloned into pENTR/D-TOPO and recombined into pAd/CMV/V5-DEST using Invitrogen's Gateway system, Carcavelos, Portugal. Adenovirus particles were generated and purified as previously described $[27,58]$. For CRMP-2, single amino acid mutations of the residue T514 to either Ala (T/A-CRMP-2) or Asp (T/D-CRMP-2) were generated, in a construct of full-length WT CRMP-2 (FLAG tagged at the N-terminus) cloned into the pRK5 expression vector, and co-transfections with EB3-mCherry or pEGFP-C1 were performed. For analysis of the relative expression of each mutant, the neuronal cell line CAD was used [59].

\section{Analysis of microtubule growth speed}

DRG neurons from eight- to ten-week-old animals were nucleofected with either a truncated version of EB3-GFP (a construct containing aminoacids 1 to 200 of EB3, artificially dimerized by the addition of the leucine zipper domain of GCN4, cloned into the pEGFP-N1 vector, that efficiently accumulates at microtubule tips [60]) or EB3mCherry, which contains full-length EB3 cloned into the mCherry-N2 vector (a kind gift from Dr Victor Small, Institute of Molecular Biotechnology, Vienna, Austria). 
After transfection, cells were left in suspension for 24 hours and then plated for 12 hours. For high resolution of EB3 comets, time-lapse recordings were performed for 100 frames every two seconds at $37^{\circ} \mathrm{C}$ on a Spinning Disk. Extended imaging periods required to correlate microtubule growth speed and axon growth were done by acquisition of 129 to 230 frames every five seconds at $37^{\circ} \mathrm{C}$ on a Spinning Disk. Kymographs were made using a Matlab script (LAPSO) [61]. The comet density (number of growing microtubules in a growth cone) was defined by counting the number of EB3 comets per frame per growth cone area. To quantify the distance of microtubule tips to the leading edge of the growth cone, a plot profile for EB3 fluorescence intensity versus distance was performed as previously described [62]. Briefly, EB3 fluorescence was measured from the tip of the growth cone up to $10 \mu \mathrm{m}$ along the growth cone using ImageJ analysis software. A minimum of 61 microtubules from at least 11 neurons was quantified.

\section{Immunocytochemistry}

DRG neurons from eight- to ten-week-old rats (either naïve or conditioned) and naïve neurons transfected with the Fyn kinase dead construct were fixed in either formalin or $2 \%$ paraformaldehyde (PFA) (in the case of transfected cells). Neurons from eight-week-old $\operatorname{GSK} 3 \beta(+/-)$ mice, cre ${ }^{+}$GSK3/lox/lox mice or the respective controls, were fixed with $2 \%$ PFA in cytoskeletal protection buffer (65 mM piperazine- $\mathrm{N}, \mathrm{N}^{\prime}$-bis (2-ethanesulfonic acid) (PIPES), $25 \mathrm{mM}$ 4-(2-hydroxyethyl)-1-piperazineethanesulfonic acid (HEPES), $10 \mathrm{mM}$ EGTA, $3 \mathrm{mM} \mathrm{MgCl}$, 0,1\% Triton X-100) for 15 minutes at room temperature. Cells were permeabilized with $0.2 \%$ triton X-100 (with the exception of cells fixed with the cytoskeletal protection buffer) and blocked with 5\% normal donkey serum in PBS. Incubation with rabbit anti-P-GSK3 $\beta$ Tyr216 (1:20; Santa Cruz Biotechnology), mouse anti-GSK3 $\beta$ (1:500; BD Transduction Laboratories, Oeiras, Portugal), rat antityrosinated tubulin (1:100; Serotec, Oxford, UK), mouse anti-acetylated tubulin (1:1000; Sigma), sheep anti-PCRMP-2Thr509/514 (1:200; Kinasourse), rabbit anti-PMAP1BThr1265 (1:100, Novus Biologicals Cambridge, UK), and mouse anti- $\beta$ III-tubulin (1:2000; Promega) antibodies in blocking buffer was performed for one hour at room temperature. For calculating the intensity ratios for P-GSK3 $\beta$ Tyr216/GSK3 $\beta$, P-CRMP-2/ $\beta$ III-tubulin and PMAP1B/ $\beta$ III-tubulin, the background of the photographs was subtracted and images were analyzed with the ImageJ plugin Ratio Plus generating an image where the mean value of the intensity ratio between the two channels in the growth cones was obtained. The ratio of acetylated versus tyrosinated $\alpha$-tubulin was determined by measuring the fluorescence intensities of acetylated $\alpha$-tubulin and of tyrosinated $\alpha$-tubulin with ImageJ. Measurements were done in the entire growth cone area selected using the tyrosinated $\alpha$-tubulin channel, after background subtraction for each channel. For the $\mathrm{cre}^{+}$GSK3/lox/lox mice, only $\mathrm{YFP}^{+}$cells were analyzed. Data were analyzed with Prism5 (GraphPad) and the mean \pm standard error of the mean (SEM) was calculated.

\section{Quantification of YFP-positive axons within the lesion area}

In $\mathrm{cre}^{+}$GSK3/lox/lox mice, we quantified the number of $\mathrm{YFP}^{+}$axons within the lesion area. The same images used for the quantification of dorsal column axons were used. Image analysis was performed using the Fiji software. After background subtraction, the threshold was automatically adjusted using the 'Li' algorithm [63]. Subsequently, the percentage of the lesion area occupied by the YFP signal was calculated.

\section{GSK3 immunohistochemistry}

Paraffin sections of DRGs (L4 to L6) from eight-weekold $\mathrm{cre}^{+}$GSK3 3 lox/lox and $\mathrm{cre}^{+}$GSK3 $\beta \mathrm{wt} / \mathrm{wt}$ mice were blocked and incubated overnight at $4{ }^{\circ} \mathrm{C}$ with the following antibodies: anti-GSK3 $\beta$ (1:100; Cell Signaling), antiGSK3 $\alpha$ (1:100; Cell Signaling), and anti-GFP (1:1000; Clontech, Lisboa, Portugal). Subsequently, incubation was performed with the respective fluorescent secondary antibodies and slides were mounted in vectashield with 4',6-diamidino-2-phenylindole (DAPI.

\section{Analysis of regeneration of dorsal column fibers}

Eight- to ten-week-old Wistar rats or GSK3 $\beta$ genetic mouse models were subjected to spinal cord dorsal hemisection and allowed to recover for five weeks. A group of animals was conditioned one week prior to SCI by transecting the left sciatic nerve. Four days prior to euthanasia, $2 \mu \mathrm{L}$ of 1\% CT-B (List Biologicals, Campbell, CA, USA) was injected in the left sciatic nerve. Animals were perfused with formalin, tissues were cryopreserved in sucrose and sectioned at $50 \mu \mathrm{m}$. Consecutive spinal cord sagittal sections were collected for free floating immunohistochemistry with anti-CT-B (1:30000; List Biologicals). Antigen detection was performed following incubation with biotinylated horse anti-goat (1:200; Vector, Peterborough, UK) either with extravidin peroxidase (1:1000; Sigma) or extravidin Alexa 568 (Invitrogen). Image analysis was done with the Photoshop CS5 (for optical microscopy) or the Fiji software (for confocal microscopy). Dorsal column fibers were quantified by counting the total number of axons within the glial scar in 1-in-3 sections. The length of the longest CT-B labeled axon found rostrally to the injury site, was measured using as the origin a vertical line placed at the rostral end of the dorsal column tract (that is, where CT-B labeling accumulates). Lesion margins were evident under phase-contrast optics as a distinct change in 
the appearance of the structure of the white and grey matter was observed. Total axon number/animal was calculated by multiplying the counted number by three.

\section{Analysis of regeneration of raphespinal serotonergic axons}

Eight- to ten-week-old GSK3 $3(+/-)$ mice and WT littermates were subjected to complete spinal cord transection and allowed to recover for five weeks. Free floating immunohistochemistry with rabbit anti-5-HT (1:20000; Immunostar, Hudson, WI, USA) was performed. Images were taken on a confocal microscope (Leica) and analysis was done with Fiji. 5-HT + axons were quantified along the rostral-caudal axis by counting the total number of axons in a 3,000 $\mu \mathrm{m}$ area caudal to the injury site in eight to ten sections per animal. Cross-sections from uninjured spinal cords obtained at the T7 level were also processed for 5$\mathrm{HT}$ immunostaining as above and 5-HT immunoreactivity was quantified in four sections/animal using FeatureJ software and normalized for the total area of the spinal cord. The glial scar area was evaluated using an anti-GFAP antibody (1:500, DAKO, Queluz, Portugal). The injury area, corresponding to the GFAP-negative area, was measured using Photoshop CS5.

\section{Behavioral assessment}

Eight- to ten-week-old animals with complete transection of the spinal cord were assessed for locomotor recovery using the Basso mouse scale [64] at day one and weekly until five weeks after the injury. The observer was blinded to the animal's genotype.

\section{Data analysis}

Data are shown as mean \pm SEM. Statistical significance was determined by Student's t test or Tukey's test (one-way analysis of variance (ANOVA)).

\section{Additional files}

Additional file 1: Movie S1. Time-lapse live cell imaging of DRG neurons either naïve or conditioned (CL) transfected with GFP-EB3, and conditioned DRG neurons transfected with GFP-EB3 plus T/D-CRMP-2 (CL + T/D-CRMP2), taken using an Andor Revolution XD Spinning Disk confocal microscope. Scale bar: $5 \mu \mathrm{m}$. Total time: 200 seconds. Acquired at one frame per two seconds. 30x speed up.

Additional file 2: Movie S2. Extended time-lapse live cell imaging of DRG neurons either naïve or conditioned (CL) transfected with GFP-EB3, and conditioned DRG neurons transfected with GFP-EB3 plus T/D-CRMP-2 (CL + T/D-CRMP2), taken using an Andor Revolution XD Spinning Disk confocal microscope. Scale bar: $5 \mu \mathrm{m}$. Total time: 770 seconds. Acquired at one frame per five seconds. $75 x$ speed up.

Additional file 3: Figure S1. Still frames from the extended time-lapse fluorescence microscopy of naïve and conditioned (CL) DRG neurons transfected with EB3-GFP, or conditioned neurons co-transfected with EB3-GFP and T/D-CRMP-2 (CL+T/D-CRMP-2). Scale bar: $5 \mu \mathrm{m}$.

Additional file 4: Movie S3. Time-lapse live cell imaging of WT or GSK3B(+/-) DRG neurons transfected with GFP-EB3 taken using an Andor Revolution XD Spinning Disk confocal microscope. Scale bar: 5 $\mu \mathrm{m}$. Total time: 200 seconds. Acquired at one frame per two seconds. 30x speed up.

Additional file 5: Movie S4. Extended time-lapse live cell imaging of WT or GSK3 $\beta(+/-)$ DRG neurons transfected with GFP-EB3 taken using an Andor Revolution XD Spinning Disk confocal microscope. Scale bar: 5 $\mu \mathrm{m}$. Total time: 645 seconds. Acquired at one frame per five seconds. 75x speed up.

Additional file 6: Figure S2. Still frames from the extended time-lapse fluorescence microscopy of WT or GSK3 $3(+/-)$ DRG neurons transfected with GFP-EB3. Scale bar: $5 \mu \mathrm{m}$.

Additional file 7: Movie S5. Time-lapse live cell imaging of cre ${ }^{+}$GSK3 $\beta w t / w t$ or $\mathrm{cre}^{+} \mathrm{GSK} 3 \beta$ lox/lox DRG neurons transfected with mCherry-EB3 (wt/wt or lox/lox, respectively), or cre ${ }^{+}$GSK3ßlox/lox DRG neurons transfected with mCherry-EB3 plus T/D-CRMP-2 (lox/lox+T/D(RMP2) taken using an Andor Revolution XD Spinning Disk confocal microscope. Scale bar: $5 \mu \mathrm{m}$. Total time: 200 seconds. Acquired at one frame per two seconds. 30x speed up.

Additional file 8: Movie S6. Extended time-lapse live cell imaging of cre $^{+}$GSK3ßWt/wt or cre ${ }^{+}$GSK3ßlox/lox DRG neurons transfected with mCherry-EB3 (wt/wt or lox/lox, respectively), or cre ${ }^{+}$GSK3ßlox/lox DRG neurons transfected with mCherry-EB3 plus T/D-CRMP-2 (lox/lox ${ }^{+}$T/D-CRMP2) taken using an Andor Revolution XD Spinning Disk confocal microscope. Scale bar: $5 \mu \mathrm{m}$. Total time: 1,150 seconds. Acquired at one frame per five seconds. $75 x$ speed up.

Additional file 9: Figure S3. Still frames from the extended time-lapse fluorescence microscopy of $\mathrm{cre}^{+}$GSK3ßwt/wt or $\mathrm{cre}^{+}$GSK3ßlox/lox DRG neurons transfected with mCherry-EB3 (wt/wt or lox/lox, respectively), or cre $^{+}$GSK3ßlox/lox DRG neurons transfected with mCherry-EB3 plus T/DCRMP-2 (lox/lox T/D-CRMP2). Scale bar: 5 um.

Additional file 10: Movie S7. Time-lapse live cell imaging of rat WT naiive neurons expressing mCherry-EB3 alone (control) or with WT MAP1B, ST/AA-MAP1B or ST/DD-MAP1B, taken using an Andor Revolution XD Spinning Disk confocal microscope. Scale bar: $5 \mu \mathrm{m}$. Total time: 200 seconds. Acquired at one frame per two seconds. 30x speed up.

Additional file 11: Movie S8. Time-lapse live cell imaging of rat WT naïve neurons expressing GFP-EB3 alone (control) or co-transfected with WT CRMP-2, T/A-CRMP-2 or T/D-CRMP-2, taken using an Andor Revolution XD Spinning Disk confocal microscope. Scale bar: $5 \mu \mathrm{m}$. Total time: 200 seconds. Acquired at one frame per two seconds. 30x speed up.

\section{Competing interests}

The authors declare that they have no competing interests.

\section{Authors' contributions}

MMS coordinated the project. MAL and MMS conceived and designed experiments and wrote the manuscript. MAL, FMM, TES, HIP, AMM, MM, SV and VFS performed experiments. MAL, TES, HIP, SV and MMS analyzed data. HP, TW, CS and JRW provided unique reagents, contributed with valuable discussions and edited the manuscript. All authors read and approved the final manuscript.

\section{Acknowledgements}

GSK3ß Ser9Ala knockin mice were a kind gift from Dr Dario Alessi (MRC Protein Phosphorylation Unit, University of Dundee). We thank Dr Phillip Gordon-Weeks (King's College, London) for useful discussions and for the MAP1B construct. At the IBMC we thank Dr Paula Sampaio, Dr Jorge Ferreira, Dr Peter Szucs, Dr Frederico Silva, Dr Luís Craveiro, Daniela Silva, Sérgio Leite, Dr Tiago Braga, Patrick Kennedy, Yago Santos and the Animal Facility staff for assisting with procedures related to this work.

This work was funded by FEDER through the Operational Competitiveness Programme- COMPETE and by National Funds through FCT- Fundação para a Ciência e a Tecnologia under the projects FCOMP-01-0124-FEDER-017455 (HMSP-ICT/0020/2010) and CIHR MOP 74711. TES was supported by the project FCOMP-01-0124-FEDER-021392 (PTDC/SAU-ORG/118863/2010). MAL was supported by FCT (SFRH/BPD/34811/2007) and by the project NORTE-07-0124-FEDER-000001-Neurodegenerative disorders (co-funded by QREN, FEDER and FCT). 


\section{Author details}

'Nerve Regeneration Group, IBMC - Instituto de Biologia Molecular e Celular, 4150-180 Porto, Portugal. 'Instituto de Ciências Biomédicas Abel Salazar ICBAS, 4050-313 Porto, Portugal. ${ }^{3}$ Department of Cell and Tissue Biology, University of California, San Francisco, CA 94145, USA. ${ }^{4}$ Diabetic and Cardiovascular Medicine, University of Dundee, Ninewells Hospital, Dundee DD1 9SY, UK. ${ }^{5}$ Samuel Lunenfeld Research Institute, Mount Sinai Hospital, University of Toronto, Toronto, ON M5G 1X5, Canada.

Received: 6 March 2014 Accepted: 7 June 2014

Published: 12 June 2014

\section{References}

1. Neumann S, Woolf CJ: Regeneration of dorsal column fibers into and beyond the lesion site following adult spinal cord injury. Neuron 1999, 23:83-91.

2. Erturk A, Hellal F, Enes J, Bradke F: Disorganized microtubules underlie the formation of retraction bulbs and the failure of axonal regeneration. J Neurosci 2007, 27:9169-9180.

3. Hellal F, Hurtado A, Ruschel J, Flynn KC, Laskowski CJ, Umlauf M, Kapitein LC, Strikis D, Lemmon V, Bixby J, Hoogenraad CC, Bradke F: Microtubule stabilization reduces scarring and causes axon regeneration after spinal cord injury. Science 2011, 331:928-931.

4. Rivieccio MA, Brochier C, Willis DE, Walker BA, D'Annibale MA, McLaughlin $K$, Siddiq A, Kozikowski AP, Jaffrey SR, Twiss JL, Ratan RR, Langley B: HDAC6 is a target for protection and regeneration following injury in the nervous system. Proc Natl Acad Sci USA 2009, 106:19599-19604.

5. Cho Y, Cavalli V: HDAC5 is a novel injury-regulated tubulin deacetylase controlling axon regeneration. EMBO J 2012, 31:3063-3078.

6. Liu CM, Hur EM, Zhou FQ: Coordinating gene expression and axon assembly to control axon growth: potential role of GSK3 signaling. Front Mol Neurosci 2012, 5:3.

7. Hughes K, Nikolakaki E, Plyte SE, Totty NF, Woodgett JR: Modulation of the glycogen synthase kinase-3 family by tyrosine phosphorylation. EMBO J 1993, 12:803-808.

8. Cole A, Frame S, Cohen P: Further evidence that the tyrosine phosphorylation of glycogen synthase kinase-3 (GSK3) in mammalian cells is an autophosphorylation event. Biochem J 2004, 377:249-255.

9. Hartigan JA, Xiong WC, Johnson GV: Glycogen synthase kinase 3beta is tyrosine phosphorylated by PYK2. Biochem Biophys Res Commun 2001, 284:485-489.

10. Lesort M, Jope RS, Johnson GV: Insulin transiently increases tau phosphorylation: involvement of glycogen synthase kinase-3beta and Fyn tyrosine kinase. J Neurochem 1999, 72:576-584.

11. Simon D, Benitez MJ, Gimenez-Cassina A, Garrido JJ, Bhat RV, Diaz-Nido J, Wandosell F: Pharmacological inhibition of GSK-3 is not strictly correlated with a decrease in tyrosine phosphorylation of residues 216/279. J Neurosci Res 2008, 86:668-674.

12. Doble BW, Woodgett JR: GSK-3: tricks of the trade for a multi-tasking kinase. J Cell Sci 2003, 116:1175-1186

13. Zhou FQ, Snider WD: Cell biology. GSK-3beta and microtubule assembly in axons. Science 2005, 308:211-214.

14. Dill J, Wang H, Zhou F, Li S: Inactivation of glycogen synthase kinase 3 promotes axonal growth and recovery in the CNS. J Neurosci 2008, 28:8914-8928.

15. Alabed YZ, Pool M, Ong Tone S, Sutherland C, Fournier AE: GSK3 beta regulates myelin-dependent axon outgrowth inhibition through CRMP4. J Neurosci 2010, 30:5635-5643.

16. McManus EJ, Sakamoto K, Armit LJ, Ronaldson L, Shpiro N, Marquez R, Alessi DR: Role that phosphorylation of GSK3 plays in insulin and Wnt signalling defined by knockin analysis. EMBO J 2005, 24:1571-1583.

17. Hoeflich KP, Luo J, Rubie EA, Tsao MS, Jin O, Woodgett JR: Requirement for glycogen synthase kinase-3beta in cell survival and NF-kappaB activation. Nature 2000, 406:86-90.

18. Smith DS, Skene JH: A transcription-dependent switch controls competence of adult neurons for distinct modes of axon growth. J Neurosci 1997, 17:646-658

19. Cao Z, Gao Y, Bryson JB, Hou J, Chaudhry N, Siddiq M, Martinez J, Spencer T, Carmel J, Hart RB, Filbin MT: The cytokine interleukin-6 is sufficient but not necessary to mimic the peripheral conditioning lesion effect on axonal growth. J Neurosci 2006, 26:5565-5573.
20. Tuszynski MH, Steward O: Concepts and methods for the study of axonal regeneration in the CNS. Neuron 2012, 74:777-791.

21. Renault-Mihara F, Katoh H, Ikegami T, Iwanami A, Mukaino M, Yasuda A, Nori S, Mabuchi Y, Tada H, Shibata S, Saito K, Matsushita M, Kaibuchi K, Okada S, Toyama Y, Nakamura M, Okano H: Beneficial compaction of spinal cord lesion by migrating astrocytes through glycogen synthase kinase-3 inhibition. EMBO Mol Med 2011, 3:682-696.

22. Patel S, Doble BW, MacAulay K, Sinclair EM, Drucker DJ, Woodgett JR: Tissue-specific role of glycogen synthase kinase 3 beta in glucose homeostasis and insulin action. Mol Cell Biol 2008, 28:6314-6328.

23. Young P, Qiu L, Wang D, Zhao S, Gross J, Feng G: Single-neuron labeling with inducible Cre-mediated knockout in transgenic mice. Nat Neurosci 2008, 11:721-728.

24. Scales TM, Lin S, Kraus M, Goold RG, Gordon-Weeks PR: Nonprimed and DYRK1A-primed GSK3 beta-phosphorylation sites on MAP1B regulate microtubule dynamics in growing axons. J Cell Sci 2009, 122:2424-2435.

25. Trivedi N, Marsh P, Goold RG, Wood-Kaczmar A, Gordon-Weeks PR: Glycogen synthase kinase-3beta phosphorylation of MAP1B at Ser1260 and Thr1265 is spatially restricted to growing axons. J Cell Sci 2005, 118:993-1005

26. Akhmanova A, Hoogenraad CC, Drabek K, Stepanova T, Dortland B, Verkerk T, Vermeulen W, Burgering BM, De Zeeuw Cl, Grosveld F, Galjart N: Clasps are CLIP-115 and -170 associating proteins involved in the regional regulation of microtubule dynamics in motile fibroblasts. Cell 2001, 104:923-935.

27. Kumar P, Lyle KS, Gierke S, Matov A, Danuser G, Wittmann T: GSK3beta phosphorylation modulates CLASP-microtubule association and lamella microtubule attachment. J Cell Biol 2009, 184:895-908.

28. Yoshimura T, Kawano Y, Arimura N, Kawabata S, Kikuchi A, Kaibuchi K: GSK-3beta regulates phosphorylation of CRMP-2 and neuronal polarity. Cell 2005, 120:137-149.

29. Sun G, Li Z, Wang X, Tang W, Wei Y: Modulation of MAPK and Akt signaling pathways in proximal segment of injured sciatic nerves. Neurosci Lett 2013, 534:205-210.

30. Saijilafu, Hur EM, Liu CM, Jiao Z, Xu WL, Zhou FQ: PI3K-GSK3 signalling regulates mammalian axon regeneration by inducing the expression of Smad1. Nat Commun 2013, 4:2690.

31. Seira O, Del Rio JA: Glycogen synthase kinase 3 beta (GSK3beta) at the tip of neuronal development and regeneration. Mol Neurobiol 2014, 49:931-944

32. Zhou FQ, Zhou J, Dedhar S, Wu YH, Snider WD: NGF-induced axon growth is mediated by localized inactivation of GSK-3beta and functions of the microtubule plus end binding protein APC. Neuron 2004, 42:897-912.

33. Jiang H, Guo W, Liang X, Rao Y: Both the establishment and the maintenance of neuronal polarity require active mechanisms: critical roles of GSK-3beta and its upstream regulators. Cell 2005, 120:123-135.

34. Jones DM, Tucker BA, Rahimtula M, Mearow KM: The synergistic effects of NGF and IGF-1 on neurite growth in adult sensory neurons: convergence on the PI 3-kinase signaling pathway. J Neurochem 2003, 86:1116-1128.

35. Garrido JJ, Simon D, Varea O, Wandosell F: GSK3 alpha and GSK3 beta are necessary for axon formation. FEBS Lett 2007, 581:1579-1586.

36. Wang $T$, Wu X, Yin C, Klebe D, Zhang JH, Qin X: CRMP-2 is involved in axon growth inhibition induced by RGMa in vitro and in vivo. Mol Neurobiol 2013, 47:903-913.

37. Sanchez S, Sayas CL, Lim F, Diaz-Nido J, Avila J, Wandosell F: The inhibition of phosphatidylinositol-3-kinase induces neurite retraction and activates GSK3. J Neurochem 2001, 78:468-481.

38. Farghaian H, Turnley AM, Sutherland C, Cole AR: Bioinformatic prediction and confirmation of beta-adducin as a novel substrate of glycogen synthase kinase 3. J Biol Chem 2011, 286:25274-25283.

39. Cole AR, Knebel A, Morrice NA, Robertson LA, Irving AJ, Connolly CN, Sutherland C: GSK-3 phosphorylation of the Alzheimer epitope within collapsin response mediator proteins regulates axon elongation in primary neurons. J Biol Chem 2004, 279:50176-50180.

40. Naska S, Park K, Hannigan GE, Dedhar S, Miller FD, Kaplan DR: An essential role for the integrin-linked kinase-glycogen synthase kinase-3 beta pathway during dendrite initiation and growth. J Neurosci 2006, 26:13344-13356.

41. Owen R, Gordon-Weeks PR: Inhibition of glycogen synthase kinase 3beta in sensory neurons in culture alters filopodia dynamics and microtubule distribution in growth cones. Mol Cell Neurosci 2003, 23:626-637.

42. Kim WY, Zhou FQ, Zhou J, Yokota Y, Wang YM, Yoshimura T, Kaibuchi $K$, Woodgett JR, Anton ES, Snider WD: Essential roles for GSK-3 s and 
GSK-3-primed substrates in neurotrophin-induced and hippocampal axon growth. Neuron 2006, 52:981-996.

43. Hur EM, Zhou FQ: GSK3 signalling in neural development. Nat Rev Neurosci 2010, 11:539-551.

44. Hur EM, Saijilafu, Lee BD, Kim SJ, Xu WL, Zhou FQ: GSK3 controls axon growth via CLASP-mediated regulation of growth cone microtubules. Genes Dev 2011, 25:1968-1981.

45. Soares S, von Boxberg Y, Lombard MC, Ravaille-Veron M, Fischer I, Eyer J, Nothias F: Phosphorylated MAP1B is induced in central sprouting of primary afferents in response to peripheral injury but not in response to rhizotomy. Eur J Neurosci 2002, 16:593-606.

46. Tortosa E, Galjart N, Avila J, Sayas CL: MAP1B regulates microtubule dynamics by sequestering EB1/3 in the cytosol of developing neuronal cells. EMBO J 2013, 32:1293-1306.

47. Bouquet $C$, Soares $S$, von Boxberg Y, Ravaille-Veron M, Propst F, Nothias F: Microtubule-associated protein 1B controls directionality of growth cone migration and axonal branching in regeneration of adult dorsal root ganglia neurons. J Neurosci 2004, 24:7204-7213.

48. Arimura N, Inagaki N, Chihara K, Menager C, Nakamura N, Amano M, Iwamatsu A, Goshima Y, Kaibuchi K: Phosphorylation of collapsin response mediator protein-2 by Rho-kinase. Evidence for two separate signaling pathways for growth cone collapse. J Biol Chem 2000, 275:23973-23980.

49. Mimura F, Yamagishi S, Arimura N, Fujitani M, Kubo T, Kaibuchi K, Yamashita T: Myelin-associated glycoprotein inhibits microtubule assembly by a Rho-kinase-dependent mechanism. J Biol Chem 2006, 281:15970-15979.

50. Zhu LQ, Zheng HY, Peng CX, Liu D, Li HL, Wang Q, Wang JZ: Protein phosphatase $2 \mathrm{~A}$ facilitates axonogenesis by dephosphorylating CRMP2. J Neurosci 2010, 30:3839-3848.

51. Khanna R, Wilson SM, Brittain JM, Weimer J, Sultana R, Butterfield A, Hensley K: Opening Pandora's jar: a primer on the putative roles of CRMP2 in a panoply of neurodegenerative, sensory and motor neuron, and central disorders. Future Neurol 2012, 7:749-771.

52. Hilton GD, Ndubuizu AN, McCarthy MM: Neuroprotective effects of estradiol in newborn female rat hippocampus. Brain Res Dev Brain Res 2004, 150:191-198.

53. Wakade C, Khan MM, De Sevilla LM, Zhang QG, Mahesh VB, Brann DW: Tamoxifen neuroprotection in cerebral ischemia involves attenuation of kinase activation and superoxide production and potentiation of mitochondrial superoxide dismutase. Endocrinology 2008, 149:367-379.

54. Pelech S, Sutter C, Zhang H: Kinetworks protein kinase multiblot analysis. Methods Mol Biol 2003, 218:99-111.

55. Fleming CE, Mar FM, Franquinho F, Saraiva MJ, Sousa MM: Transthyretin internalization by sensory neurons is megalin mediated and necessary for its neuritogenic activity. J Neurosci 2009, 29:3220-3232.

56. Norton WT, Poduslo SE: Myelination in rat brain: method of myelin isolation. J Neurochem 1973, 21:749-757.

57. Meijering E, Jacob M, Sarria JC, Steiner P, Hirling H, Unser M: Design and validation of a tool for neurite tracing and analysis in fluorescence microscopy images. Cytometry A 2004, 58:167-176.

58. Gierke S, Kumar P, Wittmann T: Analysis of microtubule polymerization dynamics in live cells. Methods Cell Biol 2010, 97:15-33.

59. Qi Y, Wang JK, McMillian M, Chikaraishi DM: Characterization of a CNS cell line, $C A D$, in which morphological differentiation is initiated by serum deprivation. J Neurosci 1997, 17:1217-1225.

60. Komarova Y, De Groot CO, Grigoriev I, Gouveia SM, Munteanu EL, Schober JM, Honnappa S, Buey RM, Hoogenraad CC, Dogterom M, Borisy GG, Steinmetz MO, Akhmanova A: Mammalian end binding proteins control persistent microtubule growth. J Cell Biol 2009, 184:691-706.

61. Pereira AJ, Maiato $\mathrm{H}$ : Improved kymography tools and its applications to mitosis. Methods 2010, 51:214-219.

62. Neukirchen D, Bradke F: Cytoplasmic linker proteins regulate neuronal polarization through microtubule and growth cone dynamics. J Neurosci 2011, 31:1528-1538.
63. Li CH, Tam PKS: An iterative algorithm for minimum cross entropy thresholding. Pattern Recognit Lett 1998, 18:771-776.

64. Basso DM, Fisher LC, Anderson AJ, Jakeman LB, McTigue DM, Popovich PG: Basso Mouse Scale for locomotion detects differences in recovery after spinal cord injury in five common mouse strains. J Neurotrauma 2006, 23:635-659.

doi:10.1186/1741-7007-12-47

Cite this article as: Liz et al:: Neuronal deletion of GSK3 $\beta$ increases microtubule speed in the growth cone and enhances axon regeneration via CRMP-2 and independently of MAP1B and CLASP2. BMC Biology 2014 12:47.

\section{Submit your next manuscript to BioMed Central and take full advantage of:}

- Convenient online submission

- Thorough peer review

- No space constraints or color figure charges

- Immediate publication on acceptance

- Inclusion in PubMed, CAS, Scopus and Google Scholar

- Research which is freely available for redistribution

Submit your manuscript at www.biomedcentral.com/submit
C) Biomed Central 